\title{
Modeling multicomponent ionic transport in groundwater with IPhreeqc coupling: Electrostatic interactions and geochemical reactions in homogeneous and heterogeneous domains
}

\author{
Muniruzzaman, Muhammad; Rolle, Massimo
}

Published in:

Advances in Water Resources

Link to article, DOI:

10.1016/j.advwatres.2016.10.013

Publication date:

2016

Document Version

Peer reviewed version

Link back to DTU Orbit

Citation (APA):

Muniruzzaman, M., \& Rolle, M. (2016). Modeling multicomponent ionic transport in groundwater with IPhreeqc coupling: Electrostatic interactions and geochemical reactions in homogeneous and heterogeneous domains. Advances in Water Resources, 98, 1-15. https://doi.org/10.1016/i.advwatres.2016.10.013

\section{General rights}

Copyright and moral rights for the publications made accessible in the public portal are retained by the authors and/or other copyright owners and it is a condition of accessing publications that users recognise and abide by the legal requirements associated with these rights.

- Users may download and print one copy of any publication from the public portal for the purpose of private study or research.

- You may not further distribute the material or use it for any profit-making activity or commercial gain

- You may freely distribute the URL identifying the publication in the public portal 
This is a Post Print of the article published on line $13^{\text {th }}$ October 2016 in Advances in Water Resources and printed December 2016, 98, 1-15. The publishers' version is available at the permanent link: http://dx.doi.org/10.1016/j.advwatres.2016.10.013

\title{
Modeling multicomponent ionic transport in groundwater with IPhreeqc coupling: electrostatic interactions and geochemical reactions in homogeneous and heterogeneous domains
}

\author{
Muhammad Muniruzzaman ${ }^{1}$ and Massimo Rolle ${ }^{1,2^{*}}$ \\ ${ }^{1}$ Center for Applied Geosciences, University of Tübingen, Hölderlinstr. 12, D-72074 \\ Tübingen, Germany \\ ${ }^{2}$ Department of Environmental Engineering, Technical University of Denmark, \\ Miljøvej, Building 115, 2800 Kgs. Lyngby, Denmark \\ *Corresponding author phone: +45 45251566; email: masro@env.dtu.dk
}

Highlights

-2-D code for multicomponent ionic transport including Coulombic interactions.

- Geochemical reactions implemented with IPhreeqc coupling.

- Applications in physically and chemically heterogeneous domains. 


\section{ABSTRACT}

2 The key role of small-scale processes like molecular diffusion and electrochemical

3 migration has been increasingly recognized in multicomponent reactive transport in

4 saturated porous media. In this study, we propose a two-dimensional multicomponent

5 reactive transport model taking into account the electrostatic interactions during transport

6 of charged ions in physically and chemically heterogeneous porous media. The modeling

7 approach is based on the local charge balance and on the description of compound-

8 specific and spatially variable diffusive/dispersive fluxes. The multicomponent ionic

9 transport code is coupled with the geochemical code PHREEQC-3 by utilizing the

10 IPhreeqc module, thus enabling to perform the geochemical calculations included in the

11 PHREEQC's reaction package. The multicomponent reactive transport code is

12 benchmarked with different 1-D and 2-D transport problems. Successively, conservative

13 and reactive transport examples are presented to demonstrate the capability of the

14 proposed model to simulate transport of charged species in heterogeneous porous media

15 with spatially variable physical and chemical properties. The results reveal that the

16 Coulombic cross-coupling between dispersive fluxes can significantly influence

17 conservative as well as reactive transport of charged species both at the laboratory and at 18 the field scale.

19 Keywords: multicomponent diffusion, electrochemical migration, IPhreeqc coupling,

20 Coulombic interactions, reactive transport modeling 


\section{1. INTRODUCTION}

23 The importance of coupling subsurface solute transport models with geochemical codes,

24 capable of simulating a wide variety of equilibrium and kinetic reactions, has been

25 increasingly recognized and has led to major developments of reactive transport codes for

26 subsurface environmental simulation (e.g., [1,2]). The coupling of fluid flow, mass

27 transport and geochemical reactions is instrumental for understanding and predicting the

28 complex interplay between physical and bio-geochemical processes in sediments and

29 groundwater systems, as well as for the quantitative interpretation of experimental

30 observations both at the laboratory and field scales. Combining flow and transport codes

31 with geochemical reaction packages has led to a first generation of now well-established

32 reactive transport simulators for both groundwater (e.g., CrunchFlow [3]; Geochemist's

33 Workbench [4]; PHT3D [5]; PHAST [6]) and unsaturated/multiphase flow (e.g.,

34 HYDROGEOCHEM [7]; TOUGHREACT [8-10]; MIN3P [11]). Developments have

35 continued over the last decade with increasing capabilities added to existing simulators as

36 well as new couplings between different transport and geochemical codes (e.g. HP1/HPx

37 [12]; PHWAT [13]; RICH-PHREEQC [14]). Impetus to such advances was certainly

38 provided by the release of modules such as IPhreeqc [15] and PhreeqcRM [16] devised to

39 increase the flexibility in interfacing the widely used USGS's geochemical reaction

40 package PHREEQC $[17,18]$ with other codes. In particular, IPhreeqc is a $\mathrm{C}++$

41 PHREEQC module designed for coupling PHREEQC's reaction capabilities (e.g.,

42 equilibrium reactions, ion exchange, surface complexation, solid solutions, mineral

43 dissolution and precipitation, as well as kinetic reactions both abiotic and microbially

44 mediated) to other software programs (for example, MATLAB ${ }^{\circledR}$, Excel $^{\circledR}$, Visual Basic $^{\circledR}$ ) 
45 and/or programming and scripting languages (for instance, C, C++, FORTRAN, Python,

46 R). IPhreeqc offers a wide range of extensive features to combine multidimensional

47 transport simulators with comprehensive geochemistry packages including

48 thermodynamic databases $[19,20]$. Recent reactive transport simulators that benefited

49 from the IPhreeqc capabilities include the couplings with COMSOL Multiphysics ${ }^{\circledR}$ (e.g.,

50 [19]; [21,22]), OpenGeoSys [23,24] and UTCHEM [25].

51 In this study we also take advantage of the IPhreeqc capabilities to explore the coupling

52 between a two-dimensional multicomponent ionic formulation of charged species

53 advective-dispersive transport and reactive processes. Many studies have demonstrated

54 the importance of electrostatic effects due to charge interactions and leading to

55 multicomponent diffusion of ions in aqueous solutions. Experimental observations have

56 shown the effects of Coulombic interactions on the diffusive mobility of major ions,

57 heavy metals and radioactive tracers both at the laboratory $[26,27]$ and at the field scale

58 [28-31]. The description of such interactions in multicomponent diffusion models is

59 usually treated by including an electromigration term in addition to the classical Fickian

60 diffusion term (e.g., [32-36]). In a series of recent laboratory flow-through experiments

61 we have shown that the role of Coulombic effects is critical not only in diffusion-

62 dominated systems but also in advection-dominated flow regimes [37-39]. In fact, the

63 results of such experiments demonstrated that the displacement of ions in porous media is

64 coupled and the electromigration effects do not vanish at high flow velocities. These

65 experimental findings represent a challenge as well as an opportunity for further

66 development of reactive transport codes. Only recently a dataset of multicomponent

67 conservative ionic transport obtained under flow-through conditions in a homogeneous 
68 porous medium has been used to benchmark the multicomponent transport capabilities of

69 the CrunchFlow and MIN3P codes [40]. However, to the best of our knowledge, the

70 behavior and effects of Coulombic interactions for multidimensional conservative and

71 reactive transport in physically and chemically heterogeneous porous media have not

72 been investigated, yet. The purpose of this contribution is to present a reactive transport

73 tool helping to address these issues in particular on the light of the increased recognition

74 of the key role of molecular diffusion for solute transport from the pore to the field scale.

75 Small scale diffusive processes have been shown to impact solute transport in flow-

76 through systems not only at the laboratory (e.g., [41-45]) but also at the larger field scale

77 (e.g., [46-54]). The impact of diffusion, which is the only true mixing process in

78 groundwater [55], on solute transport indeed does not vanish at larger scales but

79 propagates through scales also under flow-through conditions [53]. Models aiming at

80 capturing these effects in heterogeneous flow fields need to implement improved and

81 more realistic descriptions of local dispersion, linking the mechanical dispersion term to

82 spatially-variable hydraulic conductivity values and avoiding using constant dispersivities

83 that inevitably mask (or underestimate) the role of aqueous diffusion in porous media.

84 This work presents a two-dimensional reactive transport model that explicitly accounts

85 for the Coulombic interactions coupled with geochemical reactions during

86 multicomponent ionic transport in both homogeneous and heterogeneous flow-fields

87 under transient transport conditions. The modeling approach is based on a charge-

88 balanced multicomponent formulation and on the spatially variable description of local

89 hydrodynamic dispersion that is of key importance for the coupling of the fluxes of the

90 different ionic species in solution. Additionally, we couple the two-dimensional 
91 multicomponent ionic transport model with the widely used geochemical code

92 PHREEQC (version 3, [18]) by using the reaction module IPhreeqc [15]. Thus, the

93 proposed numerical reactive-transport model provides a comprehensive framework that is

94 based on the novel combination of three specific features: (i) detailed description of 95 spatially variable local hydrodynamic dispersion, (ii) multicomponent ionic formulation;

96 and (iii) extensive reaction capabilities through the coupling with PHREEQC. These

97 features represent distinctive and unique characteristics for a reactive transport simulator

98 and are particularly advantageous for performing transport simulations in physically and

99 chemically heterogeneous domains. The 2-D multicomponent model is systematically

100 benchmarked with the analytical solution of a 2-D transport problem, with experimental

101 data, and with 1-D reactive transport scenarios solved in PHREEQC. Successively,

102 application examples, with different levels of complexity, are presented to illustrate

103 transient multicomponent ionic transport and the influence of charge interactions in both

104 conservative and reactive systems in homogeneous and heterogeneous porous media.

105

106 2. MULTICOMPONENT IONIC TRANSPORT

107 The most distinguishing feature of aqueous diffusion of charged species compared to

108 non-charged solutes is the electrostatic interactions between the dissolved charged

109 species and/or with charged interfaces. Multicomponent ionic diffusion models are

110 generally used to account for these inter-species interactions during diffusive movement

111 of charged species at different scales (e.g., [27-29]; [32,33]; [35]; [56-59]). These models,

112 based on Nernst-Planck formulations, are typically derived from the chemical potential 
113 expressions by following a pragmatic extension of Fick's law (e.g., $[35,36,60]$ ).

114 Therefore, the multicomponent diffusive movement of a charged species in electrolyte

115 systems can be expressed as [29,36]:

$$
J_{i}=-D_{i} \nabla C_{i}-D_{i} C_{i} \nabla \ln \gamma_{i}-D_{i} \frac{z_{i} F}{R T} C_{i} \nabla \Phi \quad i=1,2,3, \ldots, N
$$

116 where $D_{i}$ is the self-diffusion coefficient, $C_{i}$ is the concentration of charged species $i, \gamma_{i}$ is

117 the activity coefficient, $z_{\mathrm{i}}$ is the charge number, $F$ is the Faraday's constant, $R$ is the ideal

118 gas constant, $T$ is the temperature, $\Phi$ is the electrostatic potential, and $N$ is the number of

119 species.

120 In dilute solutions and in the absence of strong ionic strength gradients, the gradient of

121 the activity coefficients (second term of Eq. 1) can be neglected [33]. Thus, the above

122 expression describing the multicomponent ionic diffusive fluxes reduces to:

$$
J_{i}=-D_{i} \nabla C_{i}-D_{i} \frac{z_{i} F}{R T} C_{i} \nabla \Phi
$$

123 This equation includes fluxes due to self-diffusion as well as electromigration, which is

124 basically induced from the electrostatic interactions, for a particular mobile species.

125 Following two physical constraints based on electroneutrality (i.e., (i) conservation of

126 local charge balance, $\sum_{i=1}^{N} z_{i} C_{i}=0$ and/or (ii) zero influx of electrical current, $\sum_{i=1}^{N} z_{i} J_{i}=0$

127 ), the gradient of $\Phi$ can be expressed as: 


$$
\nabla \Phi=\frac{\sum_{i=1}^{N}\left(z_{i} D_{i} \nabla C_{i}\right)}{\sum_{i=1}^{N}\left(z_{i}^{2} F D_{i} C_{i}\right) / R T}
$$

128 Therefore, the flux expression of Eq. (2) readily reduces to:

$$
J_{i}=-D_{i} \nabla C_{i}+\frac{z_{i} D_{i} C_{i}}{\sum_{j=1}^{N}\left(z_{j}^{2} D_{j} C_{j}\right)} \sum_{k=1}^{N}\left(z_{k} D_{k} \nabla C_{k}\right)
$$

129 This formulation directly describes the movement of a particular charged species as a 130 function of concentration gradients, self-diffusion coefficients, and charge numbers not 131 only of that ion but also of all ionic species in the electrolyte system. Eq. (4) can also be 132 further rearranged in a more compact notation that takes the form:

$$
J_{i}=-\sum_{j=1}^{N}\left(D_{i j} \nabla C_{j}\right)
$$

133 where $D_{i j}$ are the inter-diffusion coefficients that include both the pure diffusive (first

134 term, Eq. 4) and the electromigration (second term, Eq. 4) fluxes. The cross-coupled 135 inter-diffusion coefficients are defined as:

$$
D_{i j}=\delta_{i j} D_{i}-\frac{z_{i} z_{j} D_{i} D_{j} C_{i}}{\sum_{k=1}^{n}\left(z_{k}^{2} D_{k} C_{k}\right)}
$$

136 where $\delta_{i j}$ is the Kronecker delta that is equal to 1 when $i=j$ and equal to 0 if $i \neq j$.

137 In flow-through systems an analogous set of equations (Eqs. 1-6) can be derived by 138 following the above steps and replacing the pure self-diffusion coefficients by the 139 hydrodynamic dispersion coefficients [37,38]. 
141 The proposed model is implemented in MATLAB ${ }^{\circledR}$ and allows for steady-state flow,

142 transient multicomponent advective-dispersive transport and geochemical reactions, the

143 latter performed with the IPhreeqc coupling. Fig. 1 schematically illustrates the structure

144 of the multicomponent reactive transport code. Details on the model capabilities, in

145 particular the multicomponent ionic transport features and the coupling with the

146 geochemical reaction package, are discussed in the sections below.

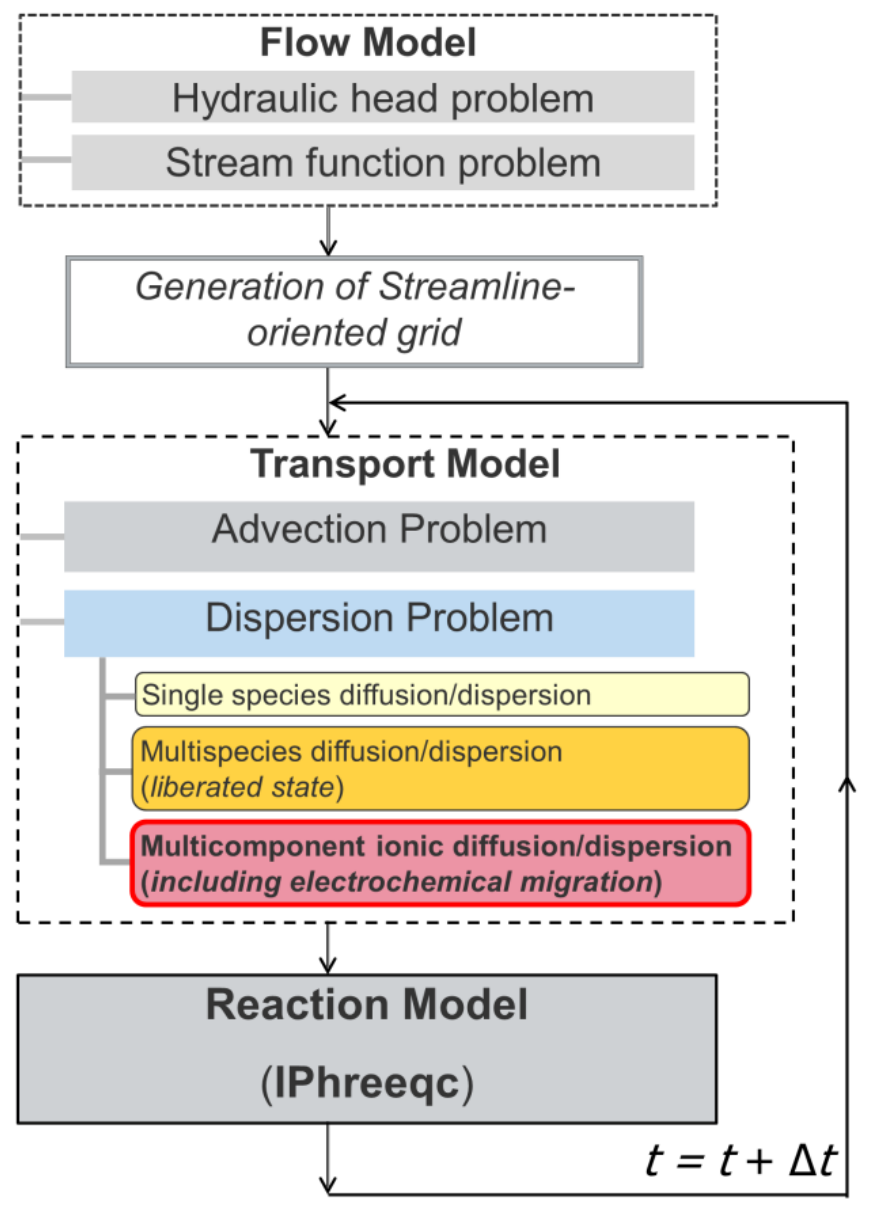

147

148 Figure 1: Schematic diagram of the structure of the multicomponent reactive transport 149 model.

150 


\section{$151 \quad 3.1$ Solution of Flow and Transport Equations}

152 The governing equation for steady-state groundwater flow in a two-dimensional domain

153 is expressed as [61]:

$$
\begin{gathered}
\nabla \cdot(\mathbf{K} \nabla h)=0 \\
\nabla \cdot\left(\mathbf{K}^{-1} \nabla \psi\right)=0
\end{gathered}
$$

154 where $h, \psi$ and $\mathbf{K}$ are hydraulic head, stream function and hydraulic conductivity tensor, 155 respectively. The groundwater flow problem (Eq. 7) is solved numerically by bilinear 156 finite elements on rectangular grid.

157 The governing equation for multicomponent ionic transport problem coupled with 158 reactive processes in two-dimensional saturated porous media reads as:

$$
\frac{\partial C_{i}}{\partial t}=-\boldsymbol{v} \cdot \nabla C_{i}+\nabla \cdot\left(\sum_{j=1}^{N} \mathbf{D}_{i j} \nabla C_{j}\right)-R_{i}
$$

159 where $t$ is time, $\boldsymbol{v}$ is the seepage velocity vector, $\mathbf{D}_{i j}$ is the tensor for cross-coupled

160 dispersion coefficients, $R_{i}$ is the reactive source/sink term. For charged compounds the

161 entries of $\mathbf{D}_{i j}$ in a two-dimensional local coordinate system, referencing along the 162 directions parallel and orthogonal to flow, are described as:

$$
\mathbf{D}_{i j}=\left[\begin{array}{cc}
\mathbf{D}_{i j}^{L} & 0 \\
0 & \mathbf{D}_{i j}^{T}
\end{array}\right]
$$

163 in which $\mathbf{D}_{i j}^{L}$ and $\mathbf{D}_{i j}^{T}$ are the matrices of longitudinal and transverse cross-coupled

164 dispersion coefficients [38], respectively. These cross-coupled terms, which allow 165 accounting for the flux of a charged species driven by both its own concentration gradient 
166 and the electrical field created by the movement of other ions present in solution, are in

167 fact analogous to inter-diffusion coefficients in Eq. (6) and can be expressed as:

$$
\begin{aligned}
& \mathbf{D}_{i j}^{L}=\delta_{i j} D_{i}^{L}-\frac{z_{i} z_{j} D_{i}^{L} D_{j}^{L} C_{i}}{\sum_{k=1}^{N}\left(z_{k}^{2} D_{k}^{L} C_{k}\right)} \\
& \mathbf{D}_{i j}^{T}=\delta_{i j} D_{i}^{T}-\frac{z_{i} z_{j} D_{i}^{T} D_{j}^{T} C_{i}}{\sum_{k=1}^{N}\left(z_{k}^{2} D_{k}^{T} C_{k}\right)}
\end{aligned}
$$

168 where $D_{i}^{L}$ and $D_{i}^{T}$ are the longitudinal and transverse hydrodynamic self-dispersion

169 coefficient of species $i$ (i.e., when a particular ion is "liberated" from the other charged

170 species in solution). The hydrodynamic dispersion coefficients, which are important

171 parameters for the realistic description of dispersive transport, are parameterized by using

172 the linear relationship proposed by Guedes de Carvalho and Delgado [62] for longitudinal

173 dispersion and a non-linear compound-specific relationship [50,63] for the transverse

174 component:

$$
\begin{aligned}
& D_{i}^{L}=D_{i}^{P}+\frac{1}{2} v d \\
& D_{i}^{T}=D_{i}^{P}+D_{i}^{a q}\left(\frac{P e_{i}^{2}}{P e_{i}+2+4 \delta^{2}}\right)^{\beta}
\end{aligned}
$$

175 where $D_{i}^{a q}$ is the aqueous diffusion coefficient, $D_{i}^{P}=D_{i}^{a q} / \tau$ is the pore diffusion 176 coefficient and $\tau$ the tortuosity of the porous medium. Since the latter is difficult to 177 determine, the pore diffusion coefficient is typically described as a function of the 178 porosity $(\theta)$ and a common approximation for unconsolidated material is $D_{i}^{P} \approx \theta D_{i}^{a q}$ 179 (e.g., Archie [64]; Boving and Grathwohl[65]). $d$ is the average grain size diameter and 
$180 P e_{i}\left(=v d / D_{i}^{a q}\right.$; with $v$ being the flow velocity $)$ is the grain Péclet number of species $i . \delta$

181 denotes the ratio between the length of a pore channel to its hydraulic radius. $\beta$ is an

182 empirical exponent that accounts for the effects of incomplete mixing in the pore

183 channels. The parameterizations of $D_{i}^{L}$ and $D_{i}^{T}$ in Eq. 11 were selected because they

184 have been validated and extensively supported by experimental data from controlled

185 flow-through experiments. Other parameterizations such as the classic model of

186 Scheidegger [66] as well as more complex models of local dispersion obtained for

187 instance from pore-scale analysis and suggesting a weak non-linearity also of the

188 longitudinal component [67] can be readily implemented. An important feature for high-

189 resolution transport simulations in heterogeneous porous media is to take into account

190 that the grain diameter $(d)$ in Eq. (11) is spatially variable and should be linked to the

191 local hydraulic conductivity value. We use the simple approximation of Hazen [68],

192 which was adopted in previous studies (e.g., [51,69]), as a relationship between the grain

193 diameter and hydraulic conductivity:

$$
d \approx c \sqrt{K}
$$

194 with the empirical proportionality constant $c=0.01 \mathrm{~m}^{0.5} \mathrm{~s}^{0.5}$. This approach ensures a 195 greatly improved representation of local dispersion compared to the common practice of 196 considering constant dispersivities even in highly heterogeneous formations. The 197 spatially variable hydrodynamic self-dispersion coefficients are of critical importance in 198 the electrostatic cross-coupling between charged species and allow providing a detailed 199 description of multicomponent ionic transport in heterogeneous formations. 
200 The multicomponent transport problem (Eq. 8) is solved numerically on streamline201 oriented grids following the method of Cirpka et al. [61]. The use of such grids, 202 constructed based on the results of the flow simulation, reduces numerical errors by 203 minimizing artificial dispersion. The advective-dispersive term is computed with the cell204 centered finite volume method (FVM) [70]. We use a sequential non-iterative operator 205 splitting approach to decouple the transport and reaction terms. For the advection 206 problem, we use upwind differentiation for spatial discretization and the explicit Euler 207 method for time integration. The dispersive fluxes are computed by the implicit Euler 208 method for integration in time. The resulting system of equations for the dispersion 209 problem is solved by using the direct matrix solver UMFPACK [71]). In multicomponent

210 ionic transport problems the system of equations becomes nonlinear due to the 211 electrostatic interactions between the dispersive fluxes of different charged species.

212 Therefore, we use an iterative scheme with a Picard loop to linearize the coupled non-

213 linear set of equations in each temporal step. The detailed computational steps for the

214 multicomponent transport and reaction calculations are summarized in Table 1.

215 For each time step, $d t$, we consider the concentration vector from the advection step (i.e.,

216 after the advective shift of concentration) as an initial guess of the Picard iteration to

217 determine the cross-coupled dispersion coefficients (Eqs. 9-10). Afterwards, we

218 determine the mobility matrix $\mathbf{M}_{\mathrm{MOB}, i}^{\mathrm{disp}}$ which results from the spatial discretization on

219 streamline-oriented grids and contains the divergence of dispersive fluxes defined by the

220 finite volume method (Step 2). The newly computed $\mathbf{D}_{i j}^{L}, \mathbf{D}_{i j}^{T}$ and $\mathbf{M}_{\mathrm{MOB}, i}^{\mathrm{disp}}$ are then used

221 to calculate the new concentration vector, $\boldsymbol{C}_{i}^{\text {disp }}$ (Step 3). Here, $\mathbf{M}_{\mathrm{STORE}, i}$ denotes the 222 storage matrix resulting from the spatial discretization and describes the discrete cell-area 
223 of each cell of the domain. $\boldsymbol{C}_{i}^{\text {adv }}$ represents the concentration vector after the advection

224 step. At each time step, the iteration in the dispersion step repeats until the concentration

225 vector reaches a constant value: i.e., when the norm of the differences among the

226 concentration values in two consecutive iterations ( $\kappa$ and $\kappa+1)$ converges to a very small

227 user-defined threshold value $(\varepsilon)$.

228 Table 1: Algorithm for transient multicomponent ionic transport and reaction 229 computation.

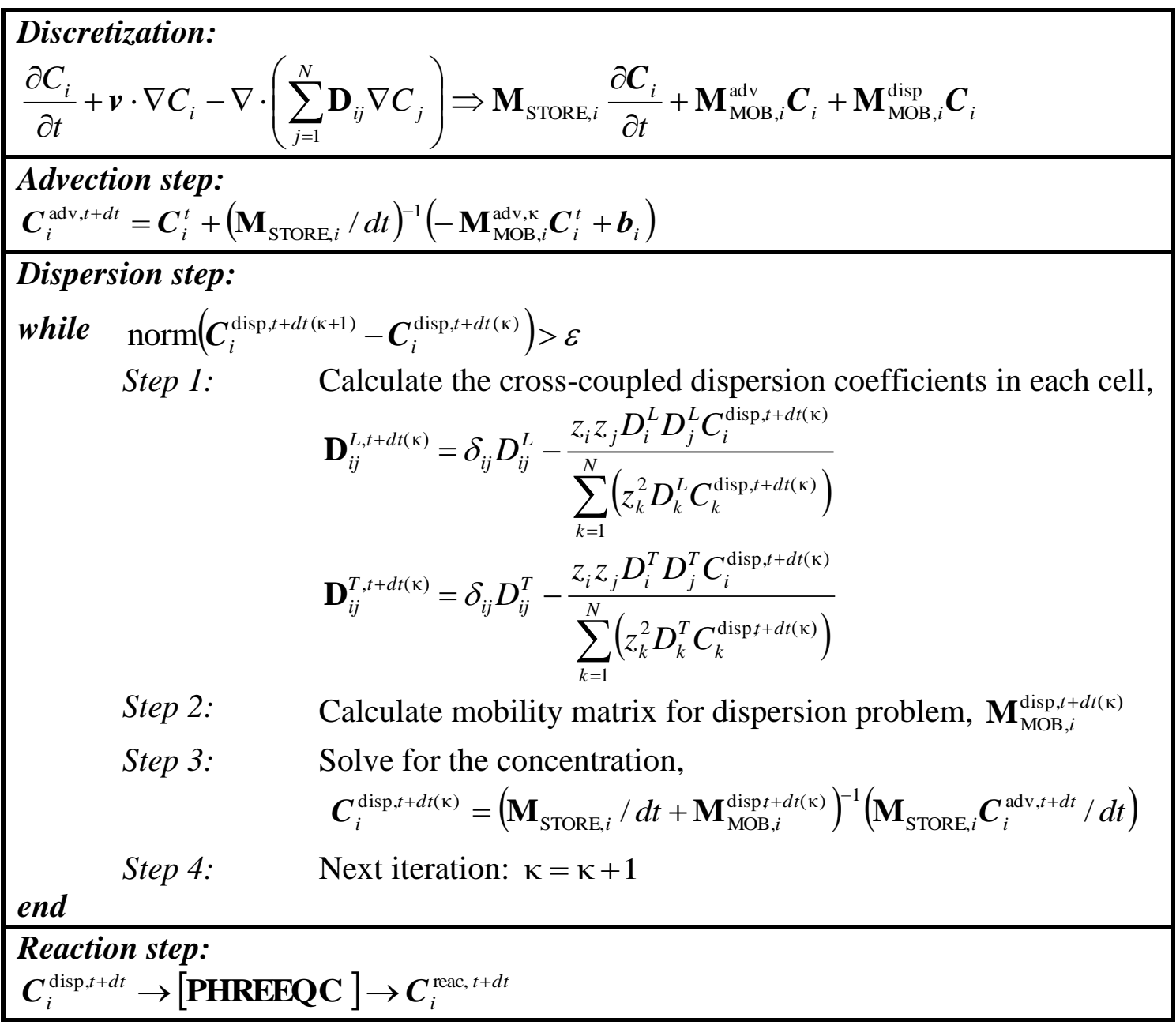


234 After the advection and dispersion steps, we perform reaction calculations with

235 PHREEQC-3 [18] by using the IPhreeqc module [15]. In our calculations, we use the

236 COM (component object model) version of IPhreeqc which allows all reaction

237 capabilities of PHREEQC to be used by any software and scripting language that can

238 interface with a Microsoft COM server, e.g., Excel $^{\circledR}$, Visual Basic ${ }^{\circledR}$, Python, or

$239 \operatorname{MATLAB}^{\circledR}[14,15]$. After updating the species concentration within the transport step,

240 the concentration vector is sequentially passed to IPhreeqc for reaction calculations. In

241 the reaction step, the simulation is performed by considering a batch reactor in each cell

242 of the 2-D model domain that contains user-defined physical and chemical properties

243 representing the reactive processes of interest. After the reaction calculations, the newly

244 updated concentration values in each cell are passed back to the transport model. Besides

245 all dissolved species, the transport calculations also include elemental oxygen $(\mathrm{O})$,

246 hydrogen $(\mathrm{H})$ and charge imbalance $(\mathrm{CB})$ as extra solution components. These

247 parameters allow PHREEQC recognizing the liquid phase (water) and tracking the charge

248 balance which is important in various geochemical calculations [19] as well as for

249 multicomponent ionic transport.

250 The formulation described above allows performing multicomponent ionic transport

251 calculations in a rigorous way that collectively includes both the electrostatic coupling of

252 dispersive fluxes and the full aqueous speciation computed by PHREEQC.

\section{4. BENCHMARK PROBLEMS}

254 The proposed multicomponent reactive transport model is benchmarked by comparing

255 the model outcomes with: (a) the analytical solution of a 2-D transport problem, (b) a 
256 high-resolution experimental dataset, (c) a classical 1-D ion-exchange problem solved 257 with PHREEQC-3 and (d) 1-D ion exchange considering multicomponent ionic transport.

258 For the sake of brevity we present in the following sections the benchmark cases (a) and

259 (d), whereas the examples (b) and (c) can be found in the Supplementary Material.

260 4.1 Benchmark of Transient Multicomponent Ionic Transport

261 In order to test the performance of our transient multicomponent ionic transport code in a 262 two-dimensional flow-through domain, we compare the simulation outcomes with an 263 analytical solution of the classical 2-D advection-dispersion equation:

$$
\frac{\partial C}{\partial t}=-v \frac{\partial C}{\partial x}+D_{L} \frac{\partial^{2} C}{\partial x^{2}}+D_{T} \frac{\partial^{2} C}{\partial z^{2}}
$$

264 The analytical solution of the advection-dispersion equation in a semi-infinite two-

265 dimensional perfectly homogeneous domain $(0<x<\infty$ and $-\infty<z<\infty)$, considering transient

266 transport of a solute initially distributed in a rectangular region with zero influx of solute

267 mass at the upstream boundary (Eqs. 15-18), is given by [72,73]:

$$
\begin{aligned}
& C(x, z, t)=\frac{C_{0}}{4}\left[\operatorname{erfc}\left(\frac{x-x_{2}-v t}{\sqrt{4 D_{i}^{L} t}}\right)-\operatorname{erfc}\left(\frac{x-x_{1}-v t}{\sqrt{4 D_{i}^{L} t}}\right)\right. \\
& \left.+\exp \left(\frac{v x}{D_{i}^{L}}\right)\left\{\operatorname{erfc}\left(\frac{x+x_{2}+v t}{\sqrt{4 D_{i}^{L} t}}\right)-\operatorname{erfc}\left(\frac{x+x_{1}+v t}{\sqrt{4 D_{i}^{L} t}}\right)\right\} \cdot \operatorname{erfc}\left(\frac{z-a}{2 \sqrt{D_{i}^{T} t}}\right)-\operatorname{erfc}\left(\frac{z+a}{2 \sqrt{D_{i}^{T} t}}\right)\right]
\end{aligned}
$$

268 The initial and boundary conditions are defined as: 


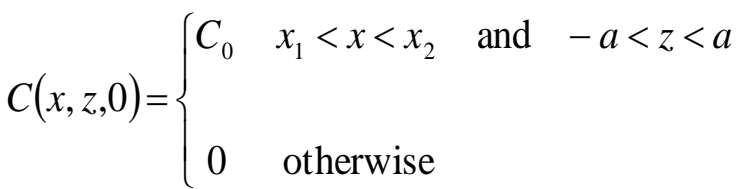

$$
\begin{aligned}
& \left.v C\right|_{x=0^{+}}=0 \\
& \frac{\partial C}{\partial x}(\infty, z, t)=0 \\
& \frac{\partial C}{\partial z}(x, \pm \infty, t)=0
\end{aligned}
$$

269 where $x_{1}$ and $x_{2}$ are the longitudinal positions delimiting the initial location of the solute

270 source. In the transverse direction, the solute is initially located between $-a$ and $a$.

271 We consider a two-dimensional homogeneous domain of $100 \mathrm{~cm} \times 12 \mathrm{~cm}$, which is

272 discretized into $100(\Delta x=1 \mathrm{~cm})$ and $240(\Delta z=0.5 \mathrm{~mm})$ cells along the longitudinal and

273 transverse dimension, respectively. The transport simulations are run for a total

274 simulation time of $t=18$ hours with a uniform horizontal velocity of $v=1.0 \mathrm{~m} / \mathrm{day}$. The

275 porosity of the flow-through system is 0.41 . We consider a rectangular solute source,

276 with dimensions of $2 \mathrm{~cm} \times 2 \mathrm{~cm}$, initially located $2 \mathrm{~cm}$ downstream of the inlet boundary,

277 between 5 and $7 \mathrm{~cm}$ along the vertical dimension (Fig. 2).

278 The simulation is performed for the transport of a single 1:1 electrolyte $(\mathrm{NaCl})$ in pure 279 ambient water. In such ionic systems, the electrostatic interactions couple the movement 280 of the cation $\left(\mathrm{Na}^{+}\right)$and the anion $\left(\mathrm{Cl}^{-}\right)$and lead to an identical displacement of the two 281 species. As a result, although the strong electrolyte $(\mathrm{NaCl})$ fully ionizes in the aqueous 282 solution and the two ions $\left(\mathrm{Na}^{+}\right.$and $\left.\mathrm{Cl}^{-}\right)$are characterized by different mobility, they 
283 travel as a single species in order to maintain electroneutrality. Hence, for this particular 284 case, the diffusion (and dispersion) of these two ions can be characterized by a single 285 diffusion coefficient (e.g., [36]):

$$
D_{\mathrm{NaCl}}=\frac{\left|z_{\mathrm{Na}^{+}}\right|+\left|z_{\mathrm{Cl}^{-}}\right|}{\left|z_{\mathrm{Na}^{+}}\right| / D_{\mathrm{Cl}^{+}}^{a q}+\left|z_{\mathrm{Cl}^{-}}\right| / D_{\mathrm{Na}^{+}}^{a q}}
$$

286 where $D_{\mathrm{NaCl}}$ represents the combined diffusion coefficient of the electrolyte. $z_{\mathrm{Na}^{+}}, z_{\mathrm{Cl}}$

287 and $D_{H^{+}}^{a q}, D_{\mathrm{Cl}^{-}}^{a q}$ are the charge and the aqueous diffusion coefficients of $\mathrm{Na}^{+}$and $\mathrm{Cl}^{-}$, 288 respectively. Self-diffusion coefficients of sodium and chloride as well as of other ions 289 used in the following sections are reported in Table 2. The value obtained combining 290 diffusion coefficients of $\mathrm{Na}^{+}$and $\mathrm{Cl}^{-}$(Eq. 19) for the salt is $D_{\mathrm{NaCl}}=1.44 \times 10^{-9} \mathrm{~m}^{2} / \mathrm{s}$.

291 Therefore, the electrostatic ionic interactions reduce the multicomponent ionic transport 292 problem into a single-species conservative transport problem. Thus, for this special case, 293 the outcomes of the 2-D transient multicomponent ionic transport model can be directly 294 compared with the results of the analytical solution (Eq. 14). In order to simulate 295 transport in flow-through systems the hydrodynamic dispersion coefficients (Eq. 11) are 296 calculated using the combined salt diffusion coefficient (Eq. 19) for the analytical 297 solution (Eq. 14) and the self-diffusion coefficients of the individual ions for the 298 numerical model. The latter takes into account the electrostatic interactions between $\mathrm{Na}^{+}$ 299 and $\mathrm{Cl}^{-}$in the pore water by coupling their dispersive fluxes as explained in Section 2 and $300 \quad$ Section 3.

301 The comparison between the multicomponent ionic transport model and the analytical 302 solution at the end of $t=18$ hours of simulation is shown in Fig. 2. The instantaneous 
303 rectangular slug source spreads and approaches a Gaussian elliptical shape during the

304 transport through the homogeneous porous medium (Fig. 2a-c). It is evident from the

305 two-dimensional concentration distributions that the concentrations both from the

306 multicomponent ionic transport simulations (Fig. 2a-b) and from the analytical solution

307 (Eq. 14, Fig. 2c) are very similar. Fig. 2 also shows the longitudinal (panel d) and

308 transverse (panel e) concentration profiles along the longitudinal and transverse axes

309 through the center of the plume. The coupled displacement of the $\mathrm{Na}^{+}$and $\mathrm{Cl}^{-}$ions results

310 in overlapping concentration of these species both in the longitudinal and in the

311 transverse direction. These profiles perfectly match with the concentration profiles of the

312 combined electrolyte (i.e., $\mathrm{NaCl}$ salt as a single uncharged species) computed with the

313 analytical solution. Thus, these results validate the accuracy of the transient

314 multicomponent ionic transport simulations in conservative two-dimensional systems.

315 Table 2: Aqueous diffusion coefficients of different ions.

\begin{tabular}{lc}
\hline Diffusion coefficients & $D^{a q}\left[\mathrm{~m}^{2} / \mathrm{s}\right]^{\mathrm{a}}$ \\
\hline $\mathrm{H}^{+}$ & $8.65 \times 10^{-9}$ \\
$\mathrm{Mg}^{2+}$ & $0.63 \times 10^{-9}$ \\
$\mathrm{Cl}^{-}$ & $1.81 \times 10^{-9}$ \\
$\mathrm{Na}^{+}$ & $1.20 \times 10^{-9}$ \\
$\mathrm{Br}^{-}$ & $1.86 \times 10^{-9}$ \\
$\mathrm{~K}^{+}$ & $1.77 \times 10^{-9}$ \\
$\mathrm{Ca}^{2+}$ & $0.71 \times 10^{-9}$ \\
$\mathrm{NO}_{3}{ }^{-}$ & $1.70 \times 10^{-9}$ \\
\hline${ }^{a}$ values from Lasaga [74], corrected for temperature and viscosity changes at $20^{\circ} \mathrm{C}$ &
\end{tabular}




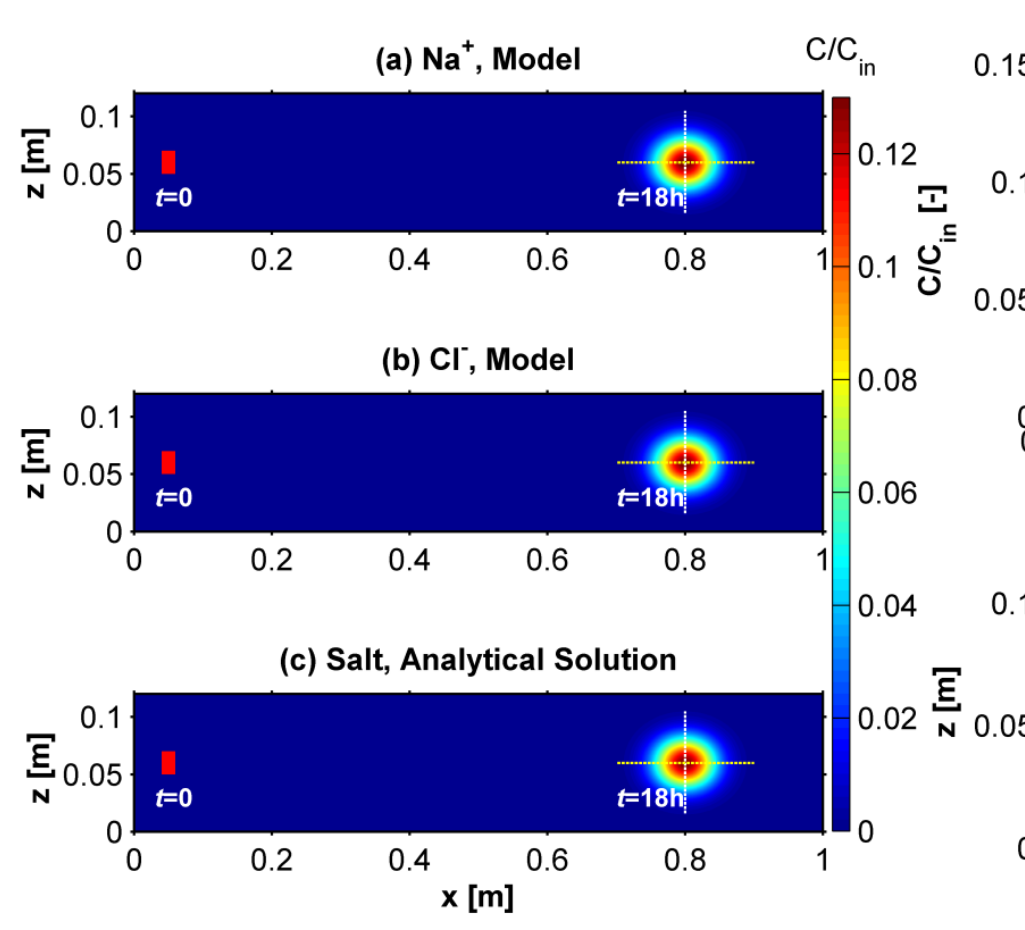

Figure 2: Comparison of the multicomponent ionic transport model and 2-D analytical solution for the transport of $\mathrm{NaCl}$ in pure water at $v=1 \mathrm{~m} /$ day: 2-D concentration distributions after $t=18$ hours (a-c); longitudinal cross sectional profiles at $z=6 \mathrm{~cm}(\mathrm{~d})$; transverse cross sectional profiles at $x=80 \mathrm{~cm}(\mathrm{e})$.

\subsection{Benchmark of IPhreeqc Coupling: Ion-Exchange with Multicomponent Ionic}

\section{Transport and Charge Interactions}

325 In order to validate the coupling of our transport code with the geochemical code

326 PHREEQC, we consider the example problem 11 of the PHREEQC-3 manual [18]. This

327 example includes the advective-dispersive transport of ionic species in a one-

328 dimensional, $8 \mathrm{~cm}$ long column containing a cation exchanger. The exchanger column,

329 initially in equilibrium with a solution containing $\mathrm{Na}^{+}, \mathrm{K}^{+}$and $\mathrm{NO}_{3}{ }^{-}$, is continuously

330 flushed with a $\mathrm{CaCl}_{2}$ solution. As a consequence, the cations $\left(\mathrm{Na}^{+}, \mathrm{K}^{+}\right.$and $\left.\mathrm{Ca}^{2+}\right)$ undergo

331 ion-exchange reactions with the exchanger and new equilibrium compositions of the

332 exchanger and the pore water are established. The comparison between the 1D 
333 PHREEQC simulation and the 2D simulation carried out with the proposed code is

334 presented in the Supplementary Material. The ion-exchange problem was also extended

335 to the case of transient multicomponent ionic transport. In this example, we specifically

336 focus on multicomponent diffusion (with charge effects) and ion-exchange problem. In

337 order to focus on the multicomponent effects, we consider diffusion-dominated transport

338 in the virtual column setup, by decreasing of a factor of ten the value of the seepage

339 velocity $(v=0.024 \mathrm{~m} /$ day $)$. The column geometry, the exchanger properties and the

340 involved ions and concentrations are kept the same as in the original example described

341 above. Instead of a single diffusion coefficient for all ionic species, species-specific

342 aqueous diffusion coefficients are used for different ions. The self-diffusion coefficients

343 used for different species are reported in Table 2. For the sake of simplicity, dispersivity

344 is neglected and thus is set to zero and the pore diffusion coefficients are assumed to be

345 identical to the aqueous diffusion coefficients (i.e., porosity, $\theta=1$ ). The 1-D PHREEQC

346 simulations are conducted by using the keyword multi_d, which allows accounting for

347 multicomponent ionic transport [29]. On the other hand, in our two-dimensional transport

348 code coupled with PHREEQC, multicomponent ionic transport calculations are

349 performed by solving Eqs. (7-10) as illustrated in Section 3 and Table 1. Fig. 3 represents

350 the simulated effluent breakthrough curves of different ionic species. Notice that, due to a

351 smaller advective velocity, diffusion becomes more dominant in this case compared to

352 the advection-dominated ion-exchange problem (Fig. S5, Supplementary Material). This

353 is reflected in the smoother temporal concentration profiles of the ionic species. The

354 evolution of $\mathrm{Cl}^{-}$front shows an interesting pattern, with a sudden increase of $\mathrm{Cl}^{-}$

355 concentration, after $\sim 1.75 \mathrm{PV}$ when $\mathrm{Ca}^{2+}$ breakthrough starts. Such behavior is due to the 
356 multicomponent ionic transport through the exchanger column and the requirement of

357 maintaining charge balance throughout the domain. Furthermore, the two simulations,

358 using PHREEQC alone in a 1-D domain and using the 2-D multicomponent ionic

359 transport code combined with PHREEQC in a uniform 2-D domain (equivalent to 1-D),

360 have the same outcome which, therefore, validates the transient multicomponent ionic

361 transport calculations coupled with chemical reactions.

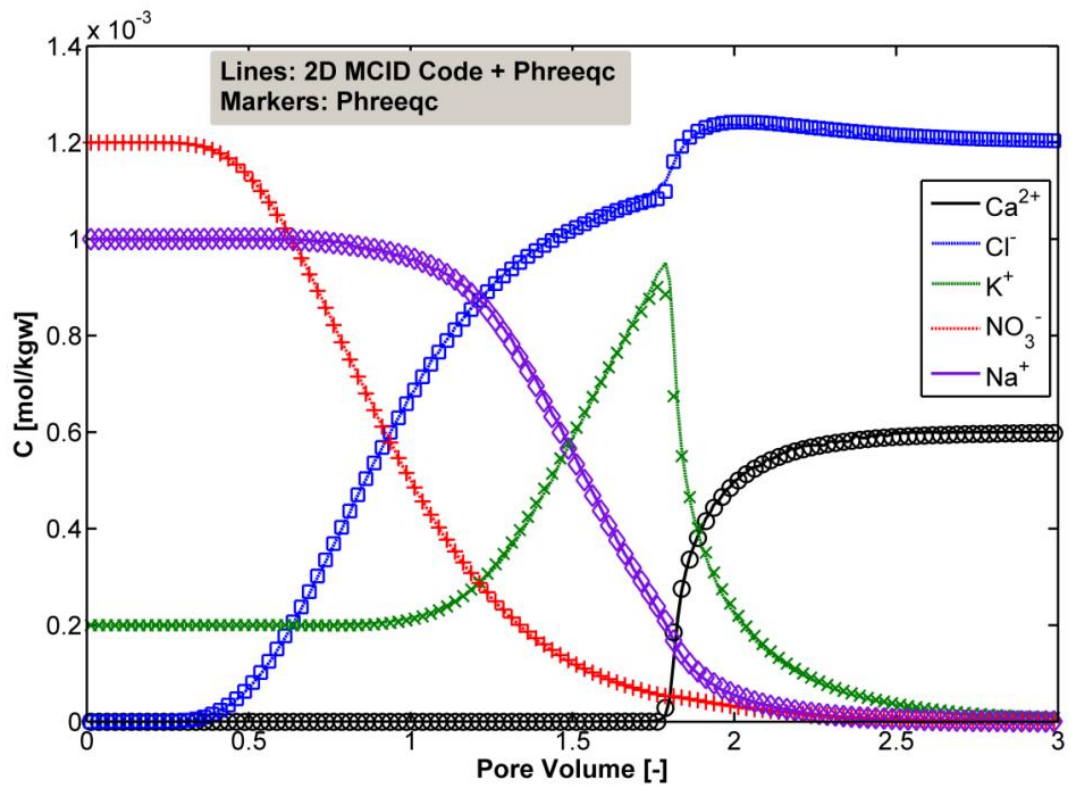

363 Figure 3: Benchmark of IPhreeqc coupling with the 2-D transport code for an example of 364 ion-exchange coupled to multicomponent ionic transport with electrochemical migration.

\section{EXAMPLES OF MULTICOMPONENT IONIC TRANSPORT SIMULATIONS}

367 In this section we present scenarios of multicomponent transport of ionic solutes in both

368 homogeneous and heterogeneous domains. Section 5.1 focuses on conservative

369 multicomponent transport of electrolyte systems. The impact of charge effects on

370 breakthrough curves and plume dilution of the different ionic species during conservative 
371 transport are analyzed. Section 5.2 illustrates multicomponent transport of charged

372 species undergoing ion-exchange reactions. We present scenarios with increasing level of

373 complexity in terms of physical heterogeneity (i.e., spatially variable hydraulic

374 conductivity) and chemical heterogeneity (i.e., spatially variable ion-exchange capacity).

\section{$375 \quad 5.1$ Conservative Transport}

\subsubsection{Simulations in Homogeneous Domain}

377 The simulations were performed to show the influence of charge interactions on transient

378 multicomponent ionic transport. We consider two different domains, a homogeneous

379 porous medium and a heterogeneous formation, at two different scales. For the

380 homogeneous case, we select a 2-D domain with dimensions of $100 \mathrm{~cm} \times 20 \mathrm{~cm}(\mathrm{~L} \times \mathrm{W})$,

381 similar to the laboratory setup recently used to investigate multicomponent ionic

382 transport [37-39], and with a uniform distribution of hydraulic conductivity and flow-

383 velocity. Such simulation domain is representative of typical laboratory bench-scale quasi

384 two-dimensional flow-through chambers packed with uniform grain sized material (e.g.,

$385[39,43,75])$. The simulations were run, by considering a rectangular slug of electrolytes as

386 initial condition, at two different horizontal flow velocities of $0.1 \mathrm{~m} /$ day and $1.0 \mathrm{~m} /$ day.

387 At each flow velocity, three different combinations of electrolyte scenarios are

388 considered: (i) transport of a single electrolyte $(\mathrm{HCl})$ in pure water; (ii) transport of a

389 single electrolyte $(\mathrm{HCl})$ in a background electrolyte solution $(\mathrm{NaBr})$; and (iii) transport of

390 mixed electrolytes $\left(\mathrm{H}^{+}, \mathrm{Mg}^{2+}\right.$ and $\left.\mathrm{Cl}^{-}\right)$in pure water. The selection of this particular set of

391 electrolytes is based on the variability of their aqueous diffusion coefficients (Table 2)

392 and demonstrates the multicomponent charge coupling effects on ions undergoing

393 conservative transport. The geometry, hydraulic and transport properties of different 
394 simulation domains are summarized in Table 3. It should be noted that these simulations

395 are run by considering the assumption that the transported ionic species do not interact

396 with the solid matrix and perfect conservative conditions exist.

397 Fig. 4 summarizes the breakthrough curves and transient flux-related dilution index for

398 different electrolyte cases at the outlet end of the homogeneous meter-scale domain. The

399 flux-related dilution index is a metric of mixing, originally developed for steady-state

400 plumes [76], that expresses dilution as the act of distributing a given solute mass flux

401 over a larger water flux and determines an effective volumetric discharge transporting the

402 solute flux at a given longitudinal cross section. For the transient multicomponent

403 transport of ionic species in flow-through domains, the flux-related dilution index of an 404 ion " $i$ " can be defined as [77]:

$$
E_{Q, i}(x, t)=\exp \left(-\int_{\Omega} p_{Q, i}(x, t) \ln p_{Q, i}(x, t) q_{x}(x, t) d \Omega\right)
$$

405 where $q_{\mathrm{x}}=v \theta$ is the longitudinal component of specific discharge, $\Omega$ is the cross406 sectional area, $\theta$ is the porosity, and $p_{Q, i}$ is the flux-related probability density function of 407 the charged species " $i$ " at time $t$ :

$$
p_{Q, i}(x, t)=\frac{C_{i}(x, t)}{\int_{\Omega} C_{i}(x, t) q_{x}(x, t)}
$$

408 The simulation outcomes at velocity of $0.1 \mathrm{~m} /$ day and $1 \mathrm{~m} /$ day are shown in Figs. 4a-f 409 and $4 \mathrm{~g}-\mathrm{l}$, respectively. For the transport of a single electrolyte $(\mathrm{HCl})$ in pure water, 410 despite having very different diffusivities (Table 2), the breakthrough curves of the cation $411\left(\mathrm{H}^{+}\right)$and anion $\left(\mathrm{Cl}^{-}\right)$are identical at both flow velocities (Fig. 4a and $4 \mathrm{~g}$ ). On the other 
412 hand, during transport in the presence of a background electrolyte, their breakthrough

413 profiles are significantly different, with the faster ion $\left(\mathrm{H}^{+}\right)$having more spread profiles

414 and lower peak concentrations compared to the slower one $\left(\mathrm{Cl}^{-}\right)$(Fig. $4 \mathrm{~b}$ and $4 \mathrm{~h}$ ). The

415 profiles of flux-related dilution index show identical values for transport in pure water

416 (Fig. $4 \mathrm{~d}$ and $4 \mathrm{j})$; whereas in the case of background electrolyte the cation $\left(\mathrm{H}^{+}\right)$plume is

417 considerably more diluted (approximately 2 times) than the anion $\left(\mathrm{Cl}^{-}\right)$plume (Fig. $4 \mathrm{e}$

418 and $4 \mathrm{k}$ ). This behavior is induced by the charge interactions between positively and

419 negatively charged species. During transport in pure water the cation and anion travel

420 together in order to fulfill the local charge balance and thus they are electrostatically

421 coupled. On the other hand, when the same ions are transported through a background

422 electrolyte solution, the domain is locally charge balanced by the background ions and,

423 consequently, the cation and anion in the solute plume can travel and subsequently dilute

424 according to their self-diffusive/dispersive properties. However, in both cases the $E_{Q, i}$

425 profiles for different ions show a monotonic increase over time at the outlet cross-section 426 of the domain (Fig. 4e and 4f). 

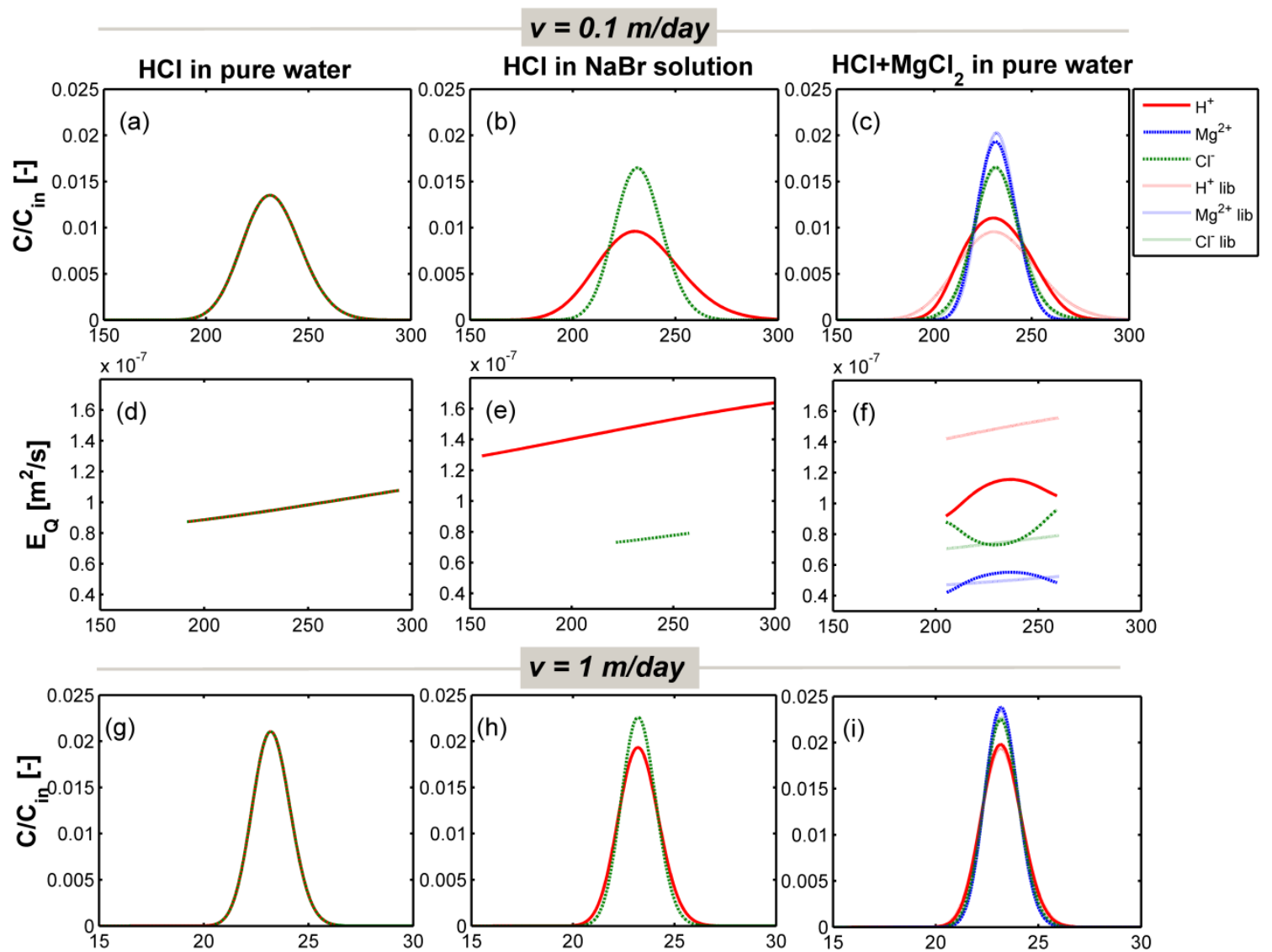

$v=1 \mathrm{~m} / \mathrm{day}$
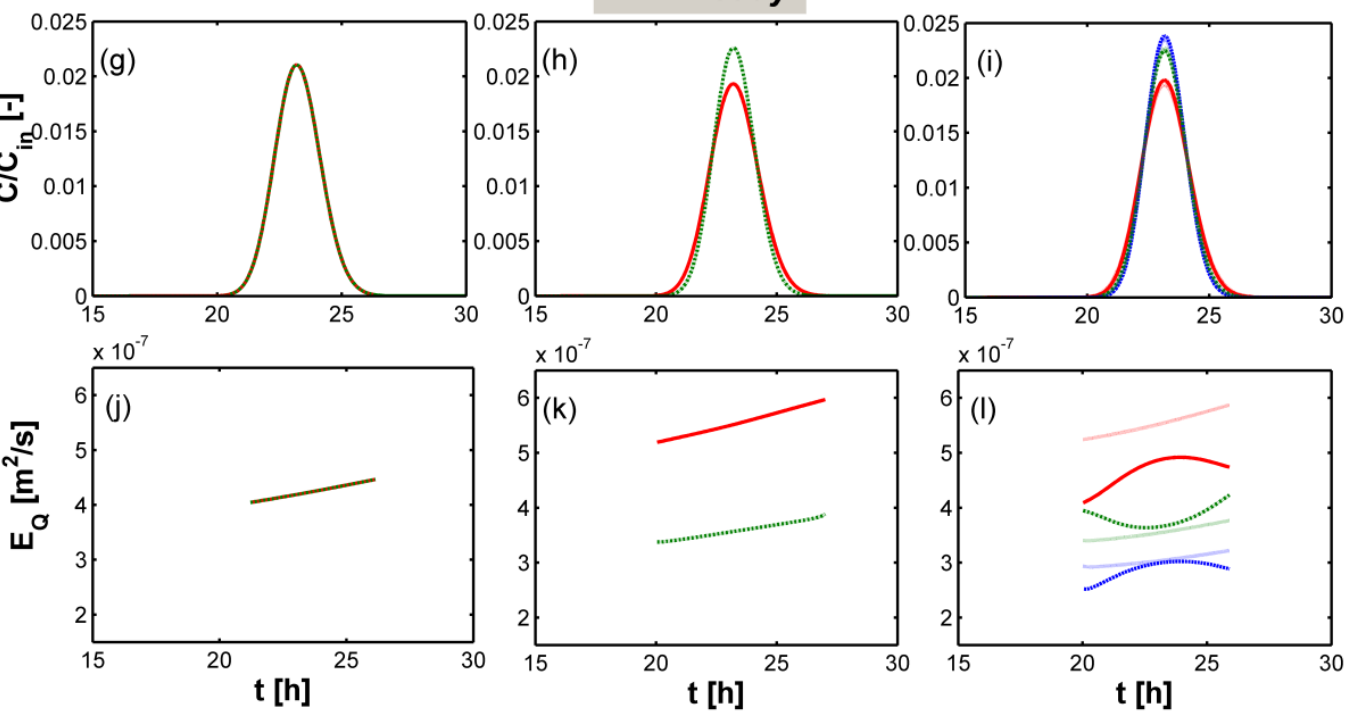

428 Figure 4: Breakthrough curves (a-c and g-i) and flux-related dilution indices (d-f and j-1) 429 for simulations at $v=0.1 \mathrm{~m} /$ day (a-f) and $v=1 \mathrm{~m} /$ day 1 (g-l) in a homogeneous domain. $430 \quad E_{Q, i}$ values are calculated for a concentration threshold equal to $10^{-6}$ of the peak 431 concentration for each species.

432 For the transport of mixed electrolytes in pure water $\left(\mathrm{H}^{+}, \mathrm{Mg}^{2+}\right.$ and $\left.\mathrm{Cl}^{-}\right)$, the breakthrough

433 curves show a distinct pattern which follows the same order as suggested by their self-

434 diffusivities (Table 2): where $\mathrm{H}^{+}$has the most spread profile with the lowest peak

435 concentration and $\mathrm{Mg}^{2+}$ shows the least spread profile and the highest peak concentration

436 (Fig. 4c). The $\mathrm{Cl}^{-}$profile lies in between those of the cations. Due to the electrostatic 
437 interaction during the displacement of the different ions, the profiles are also different 438 compared to those of transport under "liberated" conditions (i.e., when they are 439 transported as uncharged species). The behavior of the flux-related dilution index profiles

440 of the ionic species for this scenario is quite interesting. The cation dilution profiles show 441 a bulge-shape resembling a concave function. The cations have an increasing pattern of 442 dilution reaching a maximum, and afterwards decreasing again (red and blue solid lines;

443 Fig. 4f). The pattern is opposite (convex shaped) for the anion $\left(\mathrm{Cl}^{-}\right)$for which the $E_{Q}$ 444 profile decreases and reaches a minimum at around mean breakthrough time and 445 afterwards it starts increasing again (green lines; Fig. 4f). Such dilution behavior is 446 significantly different compared to the monotonic increase at their "liberated" state 447 (dotted lines; Fig. 4f) and can be explained considering the ionic interactions between the 448 transported species. In fact, at early breakthrough times, when the fringe of the plume 449 arrives at the outlet boundary, $\mathrm{H}^{+}$is more enriched compared to $\mathrm{Mg}^{2+}$ because of the 450 higher diffusive/dispersive properties of $\mathrm{H}^{+}$. As a consequence, $\mathrm{H}^{+}$is mainly responsible 451 for counterbalancing the negative charge of $\mathrm{Cl}^{-}$in the fringe area. Therefore, at the edge 452 of the plume, the dilution of $\mathrm{H}^{+}$and $\mathrm{Cl}^{-}$are similar, as reflected in their very early and 453 late time $E_{Q, i}$ values, and these ions tend to be electrostatically coupled. Thus, among 454 these two abundant species in the fringe zone, the diffusivity of $\mathrm{H}^{+}$decreases and the one 455 of $\mathrm{Cl}^{-}$increases compared to their true "liberated states" in order to maintain charge 456 balance. On the other hand, in the center of the plume, $\mathrm{Mg}^{2+}$ has a higher relative 457 concentration and hence higher contribution to counter the negative charge of $\mathrm{Cl}^{-}$. So, in 458 this case, $E_{Q, C l}$ decreases due to a stronger coupling to a slower positive ion $\left(\mathrm{Mg}^{2+}\right)$, and 459 for the same reason $\mathrm{Mg}^{2+}$ dilution increases compared to its liberated values (Fig. $4 \mathrm{f}$ ). 
460 The differences between the actual dilution of the ions' plumes compared to their

461 theoretical displacements at "liberated state" are notable for all the reported ions, as

462 shown by the different patterns of the corresponding lines in Fig. $4 \mathrm{f}$.

463 Similar patterns of concentration and dilution breakthrough curves are obtained at higher

464 velocity ( $v=1 \mathrm{~m} /$ day) (Figs. $4 \mathrm{~g}-\mathrm{l}$ ). Due to the advection-dominated transport,

465 breakthrough curves are less spread (narrow profiles with higher peak concentrations)

466 compared to their respective cases at slow velocity $(v=0.1 \mathrm{~m} /$ day $)$. Interestingly, because

467 of the higher Péclet numbers (i.e., higher values of dispersion coefficients) at $v=1 \mathrm{~m} /$ day

468 the absolute values of dilution indices $\left(E_{Q, i}\right)$ are considerably higher (approximately 5

469 times) with respect to the ones obtained at slow velocity (Figs. $4 \mathrm{j}-1,4 \mathrm{~d}-\mathrm{f})$. This implies

470 that, even though the breakthrough curves and the concentration distribution are less

471 spread, the plumes are in fact more diluted at higher seepage velocity, since the mass

472 fluxes of the different ions are distributed over larger water fluxes.

\section{5.1.2 Simulations in Heterogeneous Domain}

474 The analogous set of simulations was also performed in a heterogeneous domain to

475 investigate the large-scale effects and the influence of heterogeneity on breakthrough and

476 dilution during conservative multicomponent ionic transport. The simulations were run in

477 a randomly generated two-dimensional flow-field $(20 \mathrm{~m} \times 2.5 \mathrm{~m})$ representing a vertical

478 cross-section of a mildly heterogeneous aquifer. The hydraulic conductivity statistics are

479 consistent with those reported for the Borden aquifer [78] and the mean hydraulic

480 gradient was adjusted to produce average flow velocities of 0.1 and $1 \mathrm{~m} /$ day. The domain

481 is discretized into 200 cells $(\Delta x=10 \mathrm{~cm})$ in the horizontal direction and 250 cells $(\Delta z=1$

$482 \mathrm{~cm}$ ) in the vertical direction. The heterogeneous conductivity field is generated with an 
483 exponential covariance model and by using the spectral approach described by Dykaar

484 and Kitanidis [79]. The summary of hydraulic and transport parameters used in the

485 simulations are given in Table 3.

486 Table 3. Summary of geometry, flow and transport parameters of the homogeneous and 487 heterogeneous domains.

\begin{tabular}{lcr}
\hline Parameters & Homogeneous $^{\mathbf{a}^{\mathbf{2}}}$ & Heterogeneous $^{\mathbf{b}}$ \\
\hline Domain size $(\mathrm{L} \times \mathrm{H})[\mathrm{m}]$ & $1 \times 0.2$ & $20 \times 2.5$ \\
Discretization, $\Delta x / \Delta z[\mathrm{~cm}]$ & $0.5 / 0.1$ & $10 / 1$ \\
Slug size [m] & $0.02 \times 0.02$ & $0.4 \times 0.2$ \\
Average hydraulic conductivity [m/s] & $1.27 \times 10^{-2}$ & $9.75 \times 10^{-5}$ \\
$\sigma^{2}{ }_{\ln K}$ & - & 0.29 \\
Average horizontal flow velocity [m/day] & $0.1 ; 1$ & $0.1 ; 1$ \\
Average porosity [-] & 0.41 & 0.34 \\
\hline${ }^{a}$ Data consistent with the experimental setup of Rolle et ${ }^{2}[37]$ & &
\end{tabular}

${ }^{\mathrm{b}}$ Data consistent with the characterization of the Borden aquifer (Sudicky [78])

489 Fig. 5 shows the results of conservative transport simulation of mixed electrolytes in the

490 generated 2-D random fields for an average flow velocity of $1 \mathrm{~m} /$ day, using spatially-

491 variable local hydrodynamic dispersion coefficients in which the mechanical dispersion

492 term is linked to the hydraulic conductivity through the average grain size (Eq. 12). The

493 simulated velocities and streamlines are shown in Fig. 5a. The concentration distribution

494 of the plume containing mixed electrolytes $\left(\mathrm{HCl}\right.$ and $\left.\mathrm{MgCl}_{2}\right)$ after 7 days of simulation is

495 depicted in Fig. 5b-d. It is evident that due to heterogeneity and flow variability, the

496 shapes of the different ionic plumes are irregular. It is interesting to notice that even in

497 this spatially variable domain and under an advection-dominated regime (average $v=1$

$498 \mathrm{~m} /$ day), the compound-specific behavior of the different ions is still significant as shown

499 by the different distributions of the two cations and of the anion concentration. Due to a

500 higher diffusivive/dispersive properties, the $\mathrm{H}^{+}$plume is evidently more diluted and 
501 shows a lower peak concentration compared to the other two ions (Fig. 5b). On the other

502 hand, the $\mathrm{Mg}^{2+}$ plume is more affected by the spatial variability of the velocity

503 distribution and consequently results in a more stretched but less diluted plume with a

504 higher peak concentration (Fig. 5c). The shape of the anion $\left(\mathrm{Cl}^{-}\right)$plume appears to be in-

505 between those of the cations.
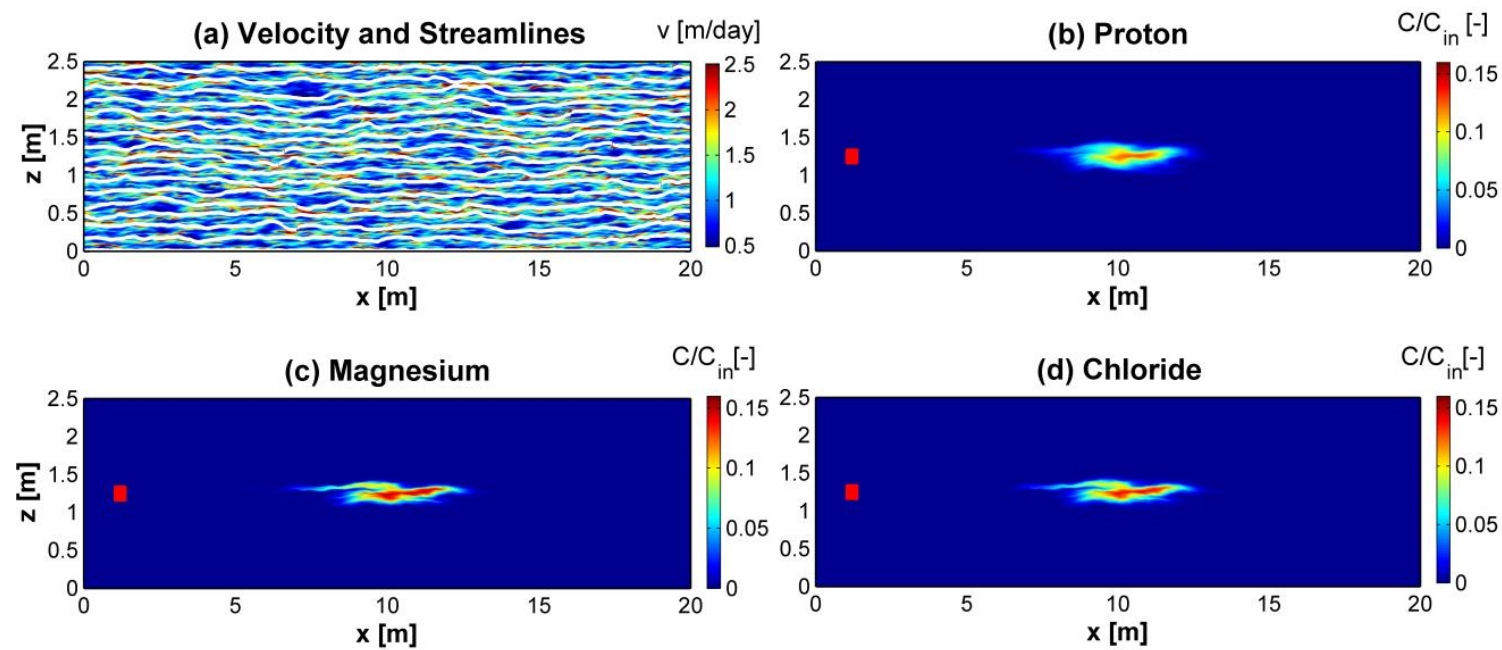

Figure 5: Seepage velocity distribution and streamlines (a); 2-D concentration maps (b-

$508 \mathrm{~d})$ for mixed electrolyte case at $v=1 \mathrm{~m} /$ day after $t=7$ days. The red rectangle represents 509 the initial location of the solute slug (b-d).

510 The breakthrough curves of concentration and flux-related dilution index $\left(E_{Q, i}\right)$, at the end

511 of the domain, are illustrated in Fig. 6 for different simulations. Although the shape of the

512 2-D concentration distribution for different ions looks very irregular (non-Gaussian; Figs.

513 5b-d), their depth-integrated breakthrough curves have almost regular shape (Figs. 6a-c,

$514 \mathrm{~g}-\mathrm{i})$ in this mildly-heterogeneous domain. 

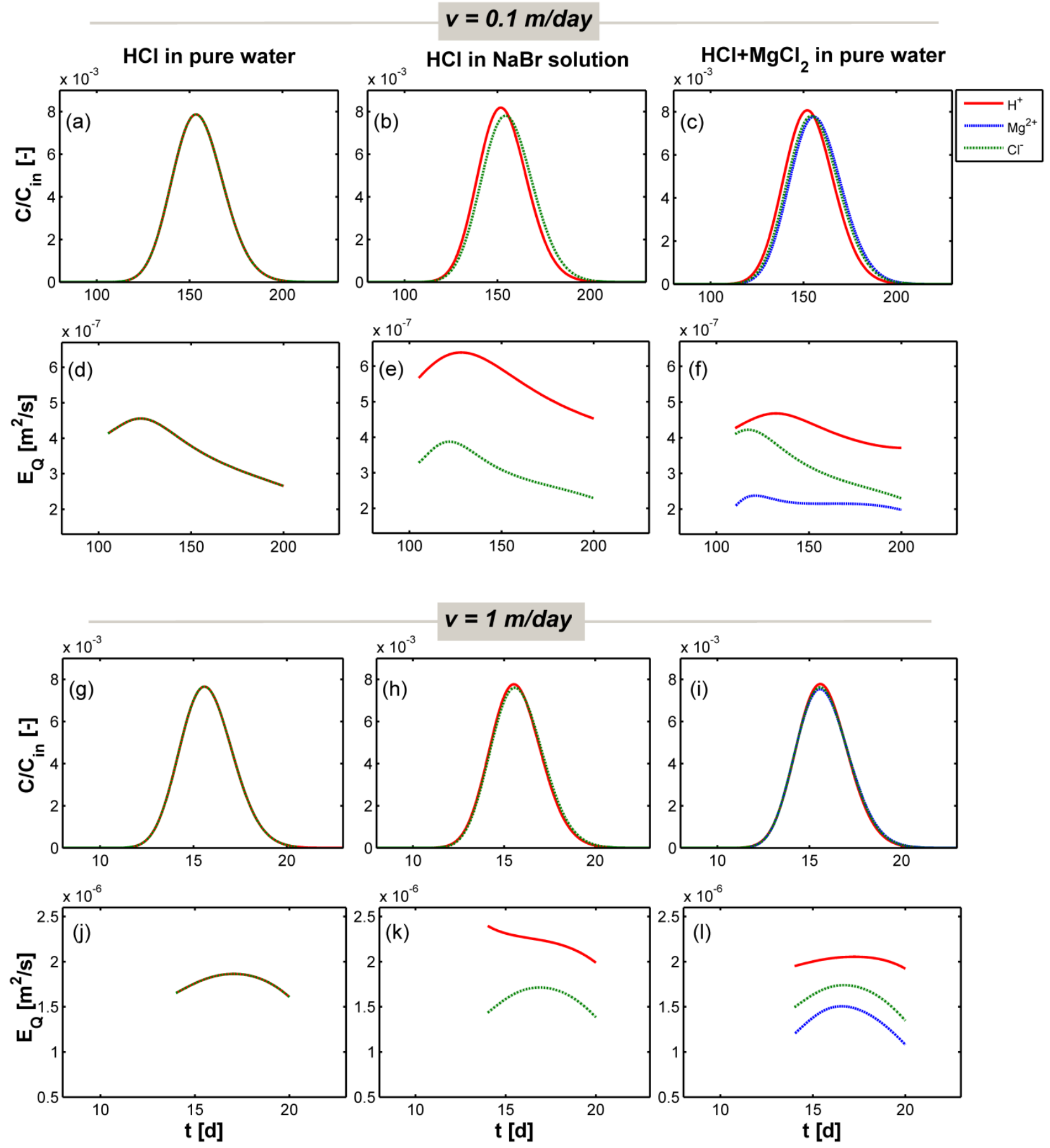

516 Figure 6: Breakthrough curves (a-c and g-i) and flux-related dilution indices (d-f and j-l) 517 for simulations at $v=0.1 \mathrm{~m} /$ day (a-f) and $1 \mathrm{~m} /$ day $(\mathrm{g}-\mathrm{l})$ in a heterogeneous domain. $E_{Q, i}$ 518 values are calculated for a concentration threshold equal to $10^{-6}$ of the peak concentration 519 for each species. 
521 For the transport of both $\mathrm{HCl}$ in a background electrolyte (Fig. $6 \mathrm{~b}, \mathrm{~h}$ ) as well as for the

522 case of mixed electrolyte in pure water (Fig. 6c,i), the differences among the ionic

523 temporal profiles are smaller compared to those observed in homogeneous domain.

524 However, the differences in dilution between the ions are still significant as shown by the 525 computed trends of $E_{Q, i}$. Unlike the regular increase of $E_{Q, i}$ in the homogeneous domain,

526 the dilution breakthroughs in the heterogeneous flow field have a non-monotonic pattern.

527 As observed in pore-scale domains [77], also for these continuum simulations such

528 behavior can be attributed to the spatial variability of the velocity field and mass transfer

529 limitations in the low-permeability zones of the heterogeneous flow field. Despite the

530 different and irregular shape of the dilution breakthroughs compared to a homogeneous

531 domain, the computed values of $E_{Q, i}$ at both flow velocities show the clear and persistent

532 effect of the electrostatic coupling also in the heterogeneous flow field. This important

533 feature can also be clearly appreciated from the maps of the ion concentration

534 distributions (Fig. 5) but would be missed if one were to analyze exclusively flux-

535 averaged concentration breakthrough curves at the outlet of the domain (Fig. 6 a-c and g536 i).

537 The effect of electrostatic coupling is also evident from the maps of the dispersive flux 538 components. As an example, Fig. 7 shows the results of transverse dispersive fluxes for

539 the case of mixed electrolytes at $v=0.1 \mathrm{~m} /$ day. It is interesting to notice the interplay

540 between the pure dispersive and the electrochemical migration components. For instance,

541 considering $\mathrm{H}^{+}$it can be clearly observed that the electromigration component can have

542 both a positive and a negative contribution to the total dispersive flux (Fig. 7g). Thus, the

543 displacement of the ion can be increased or decreased in different locations within the 
544 plume. Similar considerations are valid for the other cation and for the anion. The latter

545 shows an inversely correlated behavior with respect to $\mathrm{H}^{+}$, with displacement of $\mathrm{Cl}^{-}$ions

546 enhanced in the plume fringe, where they are mostly coupled to $\mathrm{H}^{+}$, and decreased in the

547 plume core, where the charge interaction is stronger with $\mathrm{Mg}^{2+}$. Mapping of the ionic flux

548 components helps understanding and visualizing the coupling between the transport of

549 charged species and confirms a similar behavior as noticed in the small scale

550 homogeneous domain by analyzing the dilution breakthrough curves (Fig. $4 \mathrm{f}$ and 41 ).

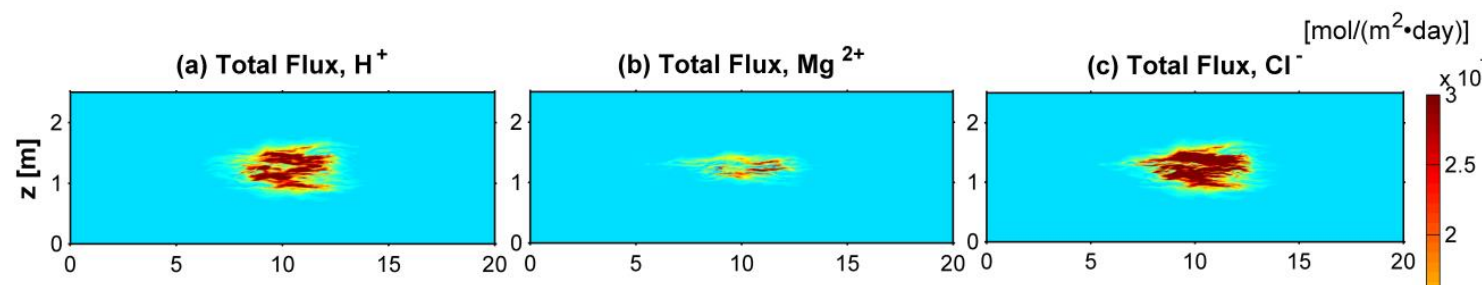

(d) Dispersive Flux, $\mathrm{H}^{+}$

(e) Dispersive Flux, $\mathrm{Mg}^{2+}$
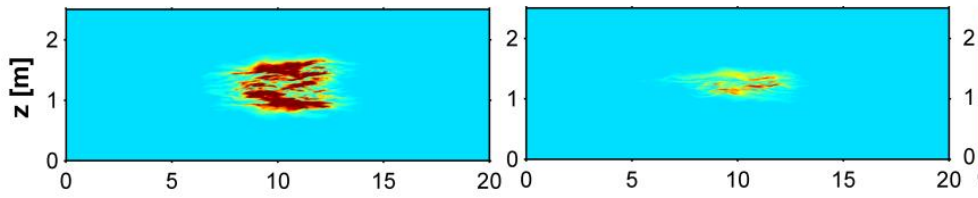

(f) Dispersive Flux, $\mathrm{Cl}^{-}$

$-1.5$

(g) Electromigration Flux, $\mathrm{H}^{+}$

(h) Electromigration Flux, $\mathrm{Mg}^{2+}$

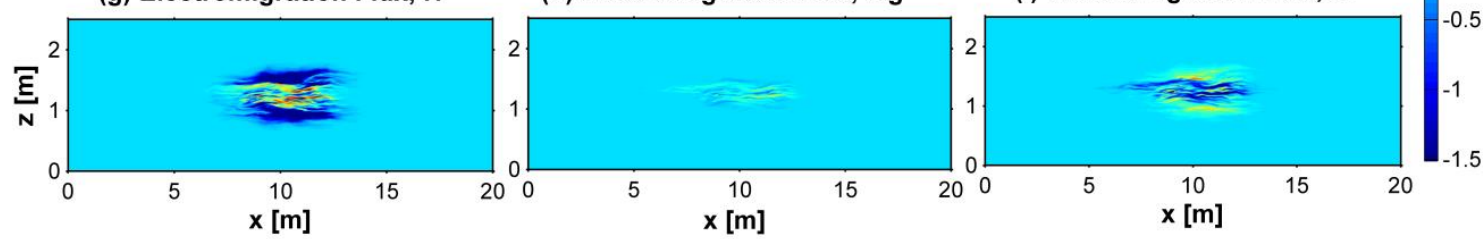

551

552

553

554

555

556

\section{7}

558

559

560

\subsection{Multicomponent Reactive Transport}

In this section we present examples of two-dimensional multicomponent ionic transport coupled to chemical reactions in physically and chemically heterogeneous domains. We consider ion-exchange reactions and, similarly to a previous study [80], we extend a 1-D 
561 example problem (Section 4.2) to two-dimensional spatially-variable domains. We focus

562 on multicomponent ionic transport and we consider a slug release of $\mathrm{CaCl}_{2}$ in a 2-D

563 domain containing $\mathrm{Na}^{+}, \mathrm{K}^{+}$and $\mathrm{NO}_{3}{ }^{-}$as initial and ambient solution. The simulations are

564 run in heterogeneous domains with different distributions of key physical and chemical

565 parameter such as the hydraulic conductivity and the cation exchange capacity (Table 4).

566 Table 4: Description of the multicomponent reactive transport scenarios.

\begin{tabular}{llccc}
\hline Scenario & K distribution & CEC distribution & Domain size & Slug size \\
\hline A & heterogeneous & homogeneous & $20 \mathrm{~m} \times 2.5 \mathrm{~m}$ & $4 \mathrm{~m} \times 0.3 \mathrm{~m}$ \\
B & heterogeneous & heterogeneous & $20 \mathrm{~m} \times 2.5 \mathrm{~m}$ & $4 \mathrm{~m} \times 0.3 \mathrm{~m}$ \\
\hline
\end{tabular}

567 The simulations were run in the randomly generated 2-D fields with the same geometry

568 and hydraulic properties of those used in Section 5.1.2. Fig. 8 shows distributions of the

569 controlling physical and chemical parameters. In both scenarios, we consider solute slugs

570 of $\mathrm{CaCl}_{2}(6 \mathrm{mM})$, initially placed $1 \mathrm{~m}$ downstream of the inflow boundary and with

571 dimensions of $4 \mathrm{~m} \times 0.3 \mathrm{~m}$, that were transported through the heterogeneous domains.

572 The inflow and initial solutions contain $\mathrm{NaNO}_{3}(1 \mathrm{mM})$ and $\mathrm{KNO}_{3}(0.2 \mathrm{mM})$.

573 Scenario A considers the effects of physical heterogeneity on the reactive transport

574 problem. In this particular scenario, a uniform value of $C E C$ (1.1 meq/L; same as [18])

575 was used throughout the entire physically heterogeneous domain. 
(a) $\log _{10} K$

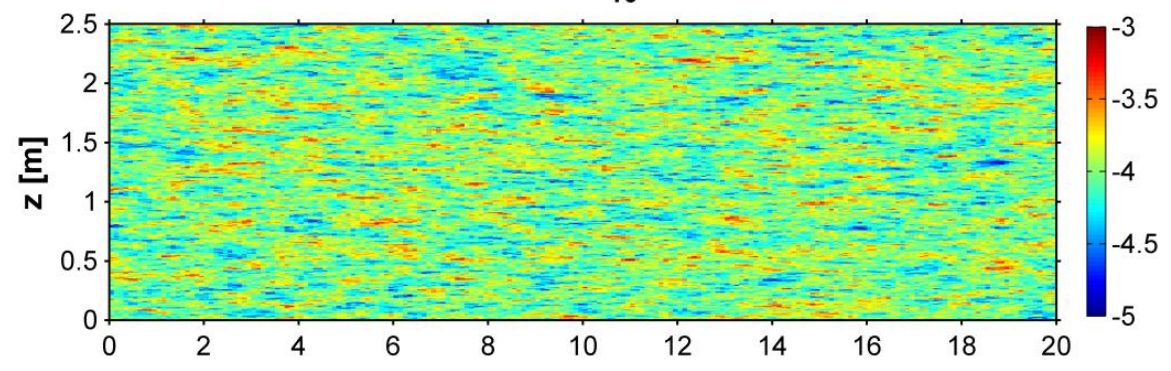

(b) $\log _{10}$ CEC

Figure 8: (a) Spatial distribution of hydraulic conductivity $K(\mathrm{~m} / \mathrm{s})$ used in the simulated

578 reactive transport scenarios A and B. (b) Spatial distribution of cation exchange capacity, 579 CEC (eq/L) used in Scenario B.

580 In Scenario B, CEC values (Fig. 8b) were attributed to each cell of the domain

581 considering a negative correlation with hydraulic conductivity as suggested in previous

582 studies (e.g., [80-83]):

$$
\ln C E C=a \ln K+b
$$

583 where $a$ and $b$ are coefficients relating the hydraulic conductivity, $K$ and the cation

584 exchange capacity, $C E C$. In a field study, Christiansen et al. [81] identified a negative

585 correlation between $K$ and $C E C$ in an aquifer $(a=-0.59)$ composed of calcareous and

586 non-calcareous layers. We base our simulations on the negative correlation proposed in

587 that study, implying that the low-permeability regions have higher cation exchange

588 capacity than the high-permeability zones (and vice versa). 
589 Fig. 9 summarizes the results of the multicomponent reactive transport simulations

590 performed in scenarios A and B. The top row of panels depict the 2-D concentration

591 distribution of the cation plumes $\left(\mathrm{Ca}^{2+} ; \mathrm{Fig} .9 \mathrm{a}, \mathrm{e}\right)$ and the lower two rows of panels show

592 the distribution of the background cations $\left(\mathrm{Na}^{+}\right.$and $\left.\mathrm{K}^{+}\right)$after 75 days of simulation. All

593 simulations are run at an average seepage velocity of $0.1 \mathrm{~m} /$ day. Fig. $9 \mathrm{a}-\mathrm{c}$ shows the

594 spatial distribution of different cations plumes in Scenario A. In this domain, the solute

595 slug $\mathrm{CaCl}_{2}$ moves with groundwater along the 2-D random flow-field containing

596 homogeneous cation-exchange properties. All the ionic plumes show irregularities

597 because of the spatially variable hydraulic conductivity and velocity distributions. The

598 displacing cation, $\mathrm{Ca}^{2+}$, shows a tailing in the upstream front and a sharper interface in

599 the downstream front of the plume. As it propagates through the domain, $\mathrm{Ca}^{2+}$ reacts with

600 the exchanger and displaces the background cations $\left(\mathrm{K}^{+}\right.$and $\left.\mathrm{Na}^{+}\right)$from the solid. Because

601 of different affinities towards the solid phase, a chromatographic sequence is clearly

602 observed among the positive ions: with $\mathrm{Na}^{+}$(lowest affinity, Fig. 9c) being the first

603 species released from the solid phase, followed by $\mathrm{K}^{+}$(Fig. 9b) and, finally, by the

604 displacing species $\mathrm{Ca}^{2+}$ (highest affinity, Fig. 9a). 
Scenario $A$

(a) $\mathrm{Ca}^{2+}$

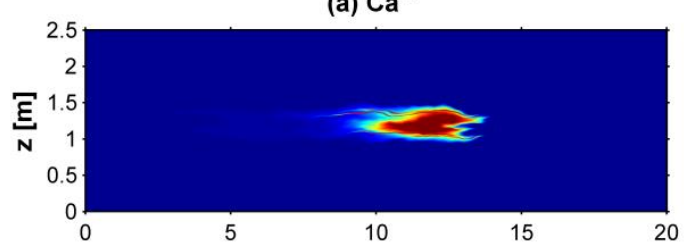

(b) $\mathrm{K}^{+}$

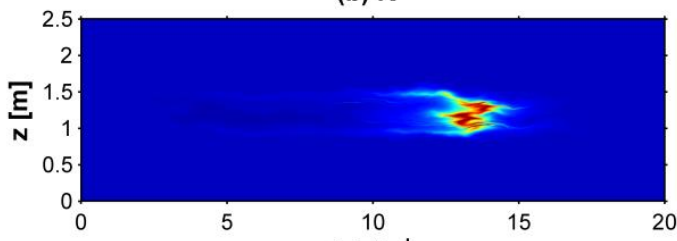

(c) $\mathrm{Na}^{+}$

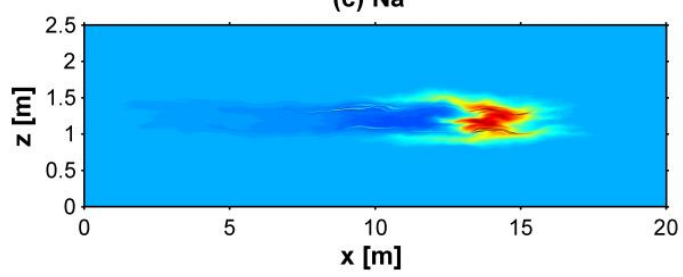

Scenario B

(d) $\mathrm{Ca}^{2+}$

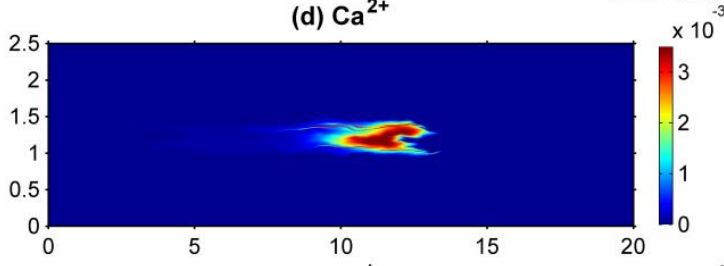

(e) $\mathrm{K}^{+}$

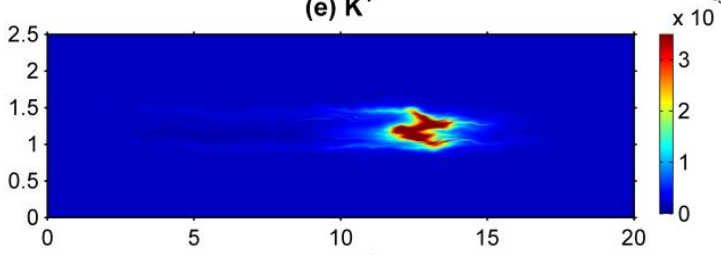

(f) $\mathrm{Na}^{+}$

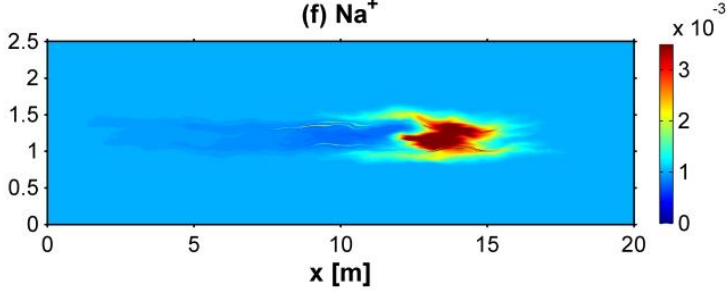

605

606 Figure 9: 2-D concentration distribution of cations in Scenario A (a-c) and B (d-f) after 60775 days of simulation.

608 The effect of $\mathrm{K}^{+}$and $\mathrm{Na}^{+}$displacement from the solids is also reflected from the fact that

609 these background cations show a surplus of dissolved concentration relative to their

610 initial values (Fig. 9b-c). The center of mass of the cation plumes also moves with

611 different apparent velocities: with $\mathrm{Na}^{+}$being the fastest species and $\mathrm{Ca}^{2+}$ being the

612 slowest one.

613 In Scenario B, the solute slug migrates with groundwater along random flow paths and in

614 a geochemically heterogeneous domain. The concentration and spreading of cation

615 plumes (Fig. 9d-f) are quite different compared to the previous scenario. The background

616 ions $\left(\mathrm{K}^{+}\right.$and $\left.\mathrm{Na}^{+}\right)$contain relatively higher concentration in the dissolved phase

617 compared to Scenario A (relative differences in the peak concentrations are $\sim 32 \%$ for $\mathrm{K}^{+}$

618 and $\sim 11 \%$ for $\mathrm{Na}^{+}$) . Conversely, $\mathrm{Ca}^{2+}$ shows a distribution that has smaller peak

619 concentration (approximately 22\%) relative to the plume in Scenario A (Fig. 9a,d). This 
620 implies that the heterogeneous distribution of geochemical properties leads to an 621 enhancement of ion-exchange reactions and more effective retention of $\mathrm{Ca}^{2+}$. After 75

622 days of simulation, the total mass of $\mathrm{Ca}^{2+}$ in the dissolved phase is $\sim 34 \%$ smaller in the

623 chemically heterogeneous domain with respect to Scenario A. This behavior can also be

624 further confirmed from the depth-integrated breakthrough curves of $\mathrm{Ca}^{2+}$ at the end of the

625 heterogeneous domains (Fig. 10a). The depth-integrated peak concentration of $\mathrm{Ca}^{2+}$ in

626 Scenario B (red solid line) is significantly smaller (approximately $\sim 5$ times) compared to

627 Scenario A (black solid line). The mean arrival of breakthrough in Scenario B is also

628 considerably delayed ( 20 days) compared to Scenario A. The dotted lines represent the

629 breakthrough curves of respective scenarios by ignoring the charge interactions (i.e., as

630 "liberated state"); while keeping the other hydraulic, transport and geochemical

631 conditions identical in the simulations. Scenario B is a random realization with the same

632 average CEC of scenario A. However, the total cation exchange capacity in the two

633 systems is different and this has an important effect on the breakthrough of calcium in the

634 two setups. Therefore, we considered an additional case in which not the average, but the

635 total CEC is the same in the two cases. The results of this additional simulation are

636 reported in Fig. 10b and show a closer behavior in terms of both arrival time and peak

637 concentration between scenario A and scenario B. It is interesting to notice that in all

638 cases a contribution due to electrochemical migration can be appreciated even in the

639 integrated profiles. Such contribution, in the considered physically and/or chemically

640 heterogeneous realizations, tends to cause an additional retardation of the calcium

641 plumes. We attribute this observation to the enhancement of $\mathrm{Ca}^{2+}$ dispersion fluxes

642 through the electrostatic coupling with the more mobile anions present in the domain. 
643 This results in lower peak concentrations and more spread $\mathrm{Ca}^{2+}$ profiles. Such differences

644 in displacement do not only influence the breakthrough of calcium but also the mass

645 recovered at the outlet. In fact, the electromigration contribution to the dispersive fluxes

646 causes enhanced displacement of calcium at the outer fringe of the plume. In these

647 regions calcium comes into contact with solid with available CEC and, thus, it is retained

648 more effectively in the solid phase. As a consequence, a lower portion of the mass is

649 recovered at the outlet.
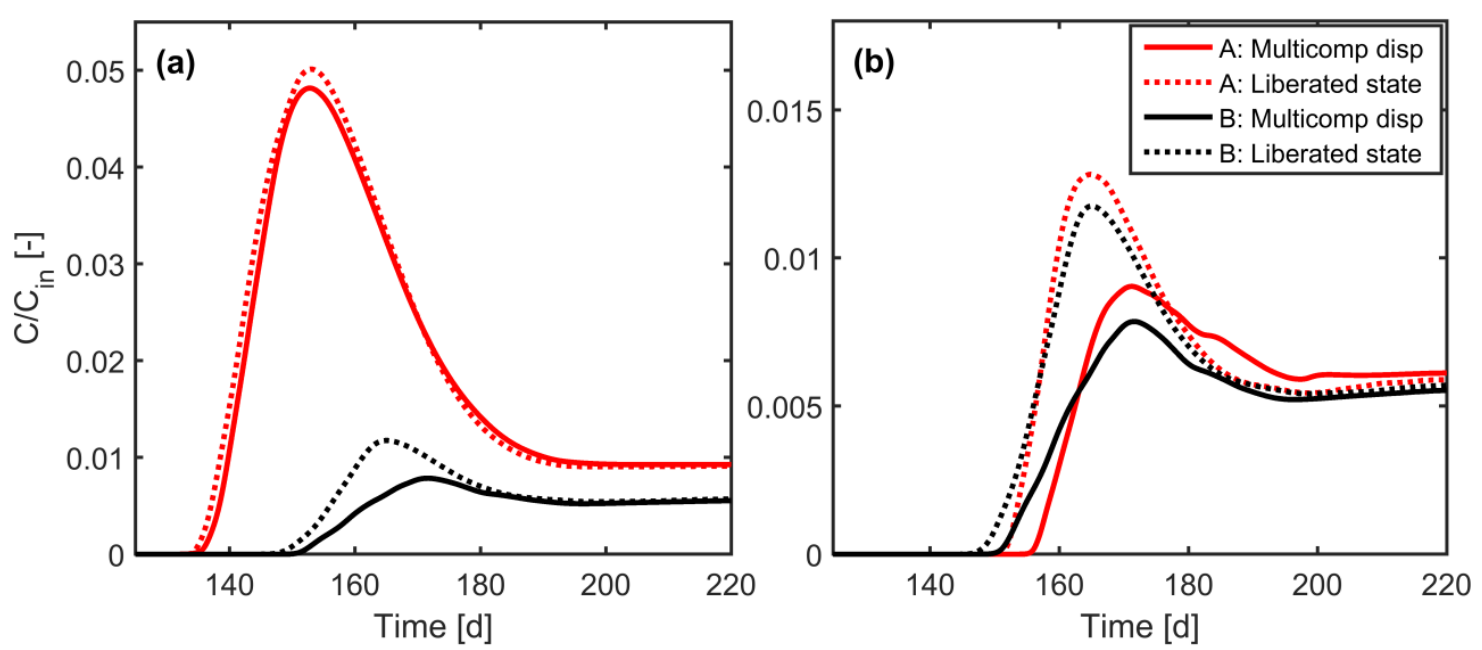

650

Figure 10: Depth-integrated breakthrough curves of $\mathrm{Ca}^{2+}$ at the end of the heterogeneous domain in Scenario A and B, considering multicomponent ionic transport (solid lines) as well as transport in "liberated" state (dotted lines). (a) Simulations with same average CEC between Scenario A and B; (b) Simulations with same total CEC between Scenario $\mathrm{A}$ and $\mathrm{B}$.

\section{SUMMARY AND CONCLUSIONS}

658 In this paper, we presented a two-dimensional multicomponent reactive transport model 659 which is capable of taking into account the electrochemical migration effects during ionic 660 transport as well as a wide range of geochemical reactions. The modeling framework is 661 based on a multicomponent formulation of diffusive/dispersive fluxes and on the 
662 compound-specific and spatially variable description of local hydrodynamic dispersion.

663 The proposed approach allows a detailed description of physical and electrochemical

664 processes during multicomponent ionic transport in both homogeneous and

665 heterogeneous formations. Additionally, the multicomponent ionic transport model is

666 coupled with the geochemical code PHREEQC, thus providing the flexibility of

667 simulating a wide variety geochemical reactions included in the PHREEQC package.

668 Two-dimensional conservative and reactive (ion-exchange) transport scenarios were

669 presented to demonstrate the capability of the developed model to simulate

670 multicomponent ionic transport in physically and chemically heterogeneous formations.

671 The simulations were performed in a homogeneous porous medium at laboratory scale, as

672 well as in heterogeneous porous media at the field scale. The simulation outcomes show

673 that the micro-scale physical (diffusion/dispersion) and/or electrochemical processes

674 (Coulombic interactions) significantly affect the macro-scale transport and dilution both

675 in the homogeneous and in the heterogeneous domains. For conservative transport, the

676 results of this study show that the coupling effects of charge interactions can be

677 appreciated from the 2-D distribution of the different ions and quantified using metrics of

678 mixing such as the flux-related dilution index. However, such effects might be

679 overlooked by only analyzing flux-averaged concentration breakthrough curves.

680 Furthermore, mapping the different components of the dispersive fluxes is also very

681 useful to understand and visualize the Coulombic coupling between the different ions and

682 the effects of electrochemical migration. The impact of electrostatic interactions is also

683 shown to be significant for the evolution of reactive plumes undergoing cation exchange

684 in physically and geochemically heterogeneous domains. For these scenarios we found 
685 that the two-dimensional concentration distributions of the transported ions, as well as

686 their integrated breakthrough curves at the outlet, are affected by the electrochemical

687 migration terms coupling the transport of the charged species. Such effects influence the

688 displacement of the dissolved ions in the pore water as well as their interaction with the

689 solid matrix, since a different displacement compared to the "liberated state" causes the

690 ions to interact with different reactive zones of the porous medium.

691 Besides the specific scenarios investigated in this study, the proposed multicomponent 692 ionic transport code can be used to explore the effects of Coulombic interactions in

693 porous media in a wide variety of reactive transport problems. This can include mineral

694 precipitation and dissolution, sorption and surface complexation reactions, propagation of

$695 \mathrm{pH}$ fronts, mobilization of heavy metals and metalloids and biodegradation reactions

696 (e.g., [84-90]). We think that the code offers particular advantages for the study of

697 transport and Coulombic interactions in flow-through systems when the aim is to provide

698 a detailed description of the effects of physical and chemical heterogeneity. The current

699 model formulation is limited to multicomponent ionic transport of dilute solutions in two-

700 dimensional formations. Further work is required to extend the framework to systems

701 with strong gradients of ionic strength and to three-dimensional transport problems. For

702 fully 3-D transport, recent experimental studies have shown a more pronounced effect of

703 diffusion and compound-specific dispersion on solute displacement and plume dilution

704 [45]. Therefore, under these conditions, the effects of Coulombic interactions on the

705 displacement of charged species are expected to be more pronounced compared to two-

706 dimensional systems. Furthermore, in fully three-dimensional anisotropic heterogeneous

707 porous media, the topology of the flow field and the possible development of twisting 

streamlines may play a major role on solute transport [91-93] and, thus, will also be of

709 interest for multicomponent ionic transport problems.

711 This work was supported by the Baden-Württemberg Stiftung under the Eliteprogram for

712 Postdocs. We would like to thank Prof. O. A. Cirpka (University of Tübingen) for

713 discussion and for providing an early version of the streamline oriented code.

\section{References}

715 [1] Steefel CI, Appelo CAJ, Arora B, Jacques D, Kalbacher T, Kolditz O, Yeh GT.

716 Reactive transport codes for subsurface environmental simulation. Computat Geosci

717 2015; 19:445-78. doi: 10.1007/s10596-014-9443-x.

718 [2] Barry DA, Prommer H, Miller CT, Engesgaard P, Brun A, Zheng C. Modelling the 719 fate of oxidisable organic contaminants in groundwater. Adv Water Resour 2002;25: 945-

720 83. doi: http://dx.doi.org/10.1016/S0309-1708(02)00044-1.

721 [3] Steefel CI, Lasaga AC. A coupled model for transport of multiple chemical-species 722 and kinetic precipitation dissolution reactions with application to reactive flow in single723 phase hydrothermal systems. Am Journal Sci 1994;294:529-92.

724 [4] Bethke C. Modelling transport in reacting geochemical systems. CR Acad Sci Ii A 1997;324:513-28.

[5] Prommer H, Barry DA, Zheng C. MODFLOW/MT3DMS-based reactive multicomponent transport modeling. Ground Water 2003, 41, 247-257.

[6] Parkhurst DL, Kipp KL, Engesgaard P, Charlton SR. PHAST - A program for simulating ground-water flow, solute transport, and multicomponent geochemical reactions. Geochim Cosmochim Acta 2005; 69.

[7] Yeh GT, VS Tripathi. HYDROGEOCHEM: A coupled model HYDROlogical transport and GEOCHEMical equilibrium of multi component systems. ORNL 6371, Oak Ridge National Laboratory 1990.

[8] Xu T, Pruess K. Modeling multiphase non-isothermal fluid flow and reactive geochemical transport in variably saturated fractured rocks 1: Methodology. Am J Sci 2001;301:16-33, doi: 10.2475/ajs.301.1.16.

[9] Xu T, Sonnenthal E, Spycher N, Pruess K. TOUGHREACT -A simulation program for non-isothermal multiphase reactive geochemical transport in variably saturated geologic media: Applications to geothermal injectivity and $\mathrm{CO} 2$ geological sequestration. Comput Geosci 2006;32:145-65. doi: http://dx.doi.org/10.1016/j.cageo.2005.06.014.

[10] Xu T, Spycher N, Sonnenthal E, Zhang G, Zheng L, Pruess K. TOUGHREACT Version 2.0: A simulator for subsurface reactive transport under non-isothermal multiphase flow conditions. Comput Geosci 2011;37:763-74. doi: http://dx.doi.org/10.1016/j.cageo.2010.10.007. 
[11] Mayer KU, Frind EO, Blowes DW. Multicomponent reactive transport modeling in variably saturated porous media using a generalized formulation for kinetically controlled reactions. Water Resour Res 2002;38:1301-21. doi: 10.1029/2001WR000862. [12] Šimunek J, Jacques D, Šejna M, Van Genuchten MT. The HP2 program for HYDRUS (2D/3D): A coupled code for simulating two-dimensional variably-saturated water flow, heat transport, and biogeochemistry in porous media, Version 1.0. PC Progress, Prague, Czech Republic 2012:76.

[13] Mao X, Prommer H, Barry DA, Langevin CD, Panteleit B, Li L. Three-dimensional model for multi-component reactive transport with variable density groundwater flow. Environ Model Softw 2006;21:615-28. doi: http://dx.doi.org/10.1016/j.envsoft.2004.11.008.

[14] Wissmeier L, Barry DA. Implementation of variably saturated flow into PHREEQC for the simulation of biogeochemical reactions in the vadose zone. Environ Model Softw 2010;25:526-38. doi: http://dx.doi.org/10.1016/j.envsoft.2009.10.001.

[15] Charlton SR, Parkhurst DL. Modules based on the geochemical model PHREEQC for use in scripting and programming languages. Comput Geosci 2011;37:1653-63. doi: http://dx.doi.org/10.1016/j.cageo.2011.02.005.

[16] Parkhurst DL, Wissmeier L. PhreeqcRM: A reaction module for transport simulators based on the geochemical model PHREEQC. Adv Water Resour 2015;83:176-89. doi: http://dx.doi.org/10.1016/j.advwatres.2015.06.001.

[17] Parkhurst DL, Appelo CAJ. User's guide to PHREEQC (Version 2) - A computer program for speciation, batch-reaction, one-dimensional transport, and inverse geochemical calculations. U.S. Geological Survey Water Resources Investigations Report 1999; 99-4259.

[18] Parkhurst DL, Appelo CAJ. Description of input and examples for PHREEQC version 3- A computer program for speciation, batch-reaction, one dimensional transport, and inverse geochemical calculations. U.S. Geological Survey Techniques and Methods 2013;6-A43:497. available only at http://pubs.usgs.gov/tm/06/a43/.

[19] Wissmeier L, Barry DA. Simulation tool for variably saturated flow with comprehensive geochemical reactions in two- and three-dimensional domains. Environ Model Softw 2011;26:210-8. doi: http://dx.doi.org/10.1016/j.envsoft.2010.07.005.

[20] Müller M, Parkhurst DL, Charlton SR. Programming PHREEQC calculations with C++ and Python - A comparative study. In: Maxwell R, Poeter E, Hill M, Zheng C, MODFLOW and More 2011 - Integrated Hydrological Modeling Proceedings 2011:632636.

[21] Nardi A, Idiart A, Trinchero P, de Vries LM, Molinero J. Interface COMSOLPHREEQC (iCP), an efficient numerical framework for the solution of coupled multiphysics and geochemistry. Comput Geosci 2014;69:10-21. doi: http://dx.doi.org/10.1016/j.cageo.2014.04.011.

[22] Nasir O, Fall M, Evgin E. A simulator for modeling of porosity and permeability changes in near field sedimentary host rocks for nuclear waste under climate change influences. Tunn Undergr Sp Tech 2014;42:122-35. doi: http://dx.doi.org/10.1016/j.tust.2014.02.010.

[23] Kolditz O, Bauer S, Bilke L, Böttcher N, Delfs JO, Fischer T, Zehner B. OpenGeoSys: An open-source initiative for numerical simulation of thermo-hydro- 
mechanical/chemical (THM/C) processes in porous media. Environ Earth Sci 2012;67:589-99. doi: 10.1007/s12665-012-1546-x.

792 [24] He W, Beyer C, Fleckenstein JH, Jang E, Kolditz O, Naumov D, Kalbacher T. A 793 parallelization scheme to simulate reactive transport in the subsurface environment with 794 OGS\#IPhreeqc 5.5.7-3.1.2. Geosci Model Dev 2015;8:3333-48. doi: 10.5194/gmd-8795 3333-2015.

796 [25] Korrani AKN, Sepehrnoori K, Delshad M. Coupling IPhreeqc with UTCHEM to 797 model reactive flow and transport. Comput Geosci 2015;82:152-69, doi: http://dx.doi.org/10.1016/j.cageo.2015.06.004.

800 J Am Chem Soc 1941;63:2008-15. doi: 10.1021/ja01852a063.

801 [27] Liu CX, Shang JY, Zachara JM. Multispecies diffusion models: A study of uranyl 802 species diffusion. Water Resour Res 2011; 47: W12514. 803 http://dx.doi.org/10.1029/2011WR010575.

804 [28] Giambalvo ER, Steefel CI, Fisher AT, Rosenberg ND, Wheat CG. Effect of fluid805 sediment reaction on hydrothermal fluxes of major elements, eastern flank of the Juan de 806 Fuca Ridge. Geochim Cosmochim Acta 2002;66:1739-57. doi: 10.1016/S0016-

\section{7(01)00878-X.}

[29] Appelo CAJ, Wersin P. Multicomponent diffusion modeling in clay systems with application to the diffusion of tritium, iodide, and sodium in opalinus clay. Environ Sci Tech 2007;41:5002-7. doi: Doi 10.1021/Es0629256.

[30] Appelo CAJ, Vinsot A, Mettler S, Wechner S. Obtaining the porewater composition of a clay rock by modeling the in- and out-diffusion of anions and cations from an in-situ experiment. J Contam Hydrol 2008;101:67-76. doi: DOI 10.1016/j.jconhyd.2008.07.009. [31] Appelo CAJ, Van Loon LR, Wersin P. Multicomponent diffusion of a suite of tracers (HTO, Cl, Br, I, Na, Sr, Cs) in a single sample of Opalinus Clay. Geochim Cosmochim Acta 2010;74:1201-19. doi: 10.1016/j.gca.2009.11.013.

[32] Ben-Yaakov S. Diffusion of sea water ions-I. Diffusion of sea water into a dilute solution. Geochim Cosmochim Acta 1972;36:1395-406. doi: 10.1016/00167037(72)90069-5.

[33] Lasaga AC. The treatment of multi-component diffusion and ion pairs in diagenetic fluxes. Am J Sci 1979;279:324-46. doi: 10.2475/ajs.279.3.324.

[34] Felmy AR, Weare JH. Calculation of multicomponent ionic-diffusion from zero to high-concentration 1. The System Na-K-Ca-Mg-Cl-SO $\mathrm{S}_{4}-\mathrm{H}_{2} \mathrm{O}$ at 25-degrees-C. Geochim Cosmochim Acta 1991;55:113-31. doi: Doi 10.1016/0016-7037(91)90405-T.

[35] Boudreau BP, Meysman FJR, Middelburg JJ. Multicomponent ionic diffusion in porewaters: Coulombic effects revisited. Earth Planet Sci Lett 2004;222:653-66. doi: 10.1016/j.epsl.2004.02.034.

[36] Cussler EL. Diffusion : Mass transfer in fluid systems. 3rd ed. Cambridge University Press, Cambridge, New York 2009.

[37] Rolle M, Muniruzzaman M, Haberer CM, Grathwohl P. Coulombic effects in advection-dominated transport of electrolytes in porous media: Multicomponent ionic dispersion. Geochim Cosmochim Acta 2013;120:195-205. doi: http://dx.doi.org/10.1016/j.gca.2013.06.031.

[38] Muniruzzaman M, Haberer CM, Grathwohl P, Rolle M. Multicomponent ionic dispersion during transport of electrolytes in heterogeneous porous media: Experiments 
and model-based interpretation. Geochim Cosmochim Acta 2014;141:656-69. doi: http://dx.doi.org/10.1016/j.gca.2014.06.020.

838 [39] Muniruzzaman M, Rolle M. Impact of multicomponent ionic transport on $\mathrm{pH}$ fronts propagation in saturated porous media. Water Resour Res 2015;51:6739-55. doi: 10.1002/2015WR017134.

[40] Rasouli P, Steefel CI, Mayer KU, Rolle M. Benchmarks for multicomponent diffusion and electrochemical migration. Computat Geosci 2015;19:523-33. doi: 10.1007/s10596-015-9481-z.

[41] Bauer RD, Rolle M, Bauer S, Eberhardt C, Grathwohl P, Kolditz O, Griebler C. Enhanced biodegradation by hydraulic heterogeneities in petroleum hydrocarbon plumes. J Contam Hydrol 2009;105:56-68. doi: 10.1016/j.jconhyd.2008.11.004.

[42] Rolle M, Chiogna G, Bauer R, Griebler C, Grathwohl P. Isotopic fractionation by transverse dispersion: Flow-through microcosms and reactive transport modeling study. Environ Sci Tech 2010;44:6167-73. doi: 10.1021/es101179f.

[43] Haberer CM, Rolle M, Cirpka OA, Grathwohl P. Oxygen transfer in a fluctuating capillary fringe. Vadose Zone J 2012;11. doi: 10.2136/Vzj2011.0056.

[44] Hochstetler DL, Rolle M, Chiogna G, Haberer CM, Grathwohl P, Kitanidis PK. Effects of compound-specific transverse mixing on steady-state reactive plumes: Insights from pore-scale simulations and Darcy-scale experiments. Adv Water Resour 2013;54:110. doi: 10.1016/j.advwatres.2012.12.007.

[45] Ye Y, Chiogna G, Cirpka OA, Grathwohl P, Rolle M. Enhancement of plume dilution in two-dimensional and three-dimensional porous media by flow focusing in high-permeability inclusions. Water Resour Res 2015;51:5582-602. doi: 10.1002/2015WR016962.

[46] Fiori A, Jankovic I, Dagan G. The impact of local diffusion upon mass arrival of a passive solute in transport through three-dimensional highly heterogeneous aquifers. Adv Water Resour 2011;34:1563-73. doi: 10.1016/j.advwatres.2011.08.010.

[47] Hadley PW, Newell C. The new potential for understanding groundwater contaminant transport. Groundwater 2014;52:174-86. doi: 10.1111/gwat.12135.

[48] LaBolle EM, Fogg GE. Role of molecular diffusion in contaminant migration and recovery in an alluvial aquifer system. Trans Porous Med 2001;42:155-79. doi: 10.1023/A:1006772716244.

[49] Liu CX, Ball WP. Back diffusion of chlorinated solvent contaminants from a natural aquitard to a remediated aquifer under well-controlled field conditions: Predictions and measurements. Ground Water 2002;40:175-84. doi: 10.1111/j.17456584.2002.tb02502.x.

[50] Chiogna G, Eberhardt C, Grathwohl P, Cirpka OA, Rolle M. Evidence of compound-dependent hydrodynamic and mechanical transverse dispersion by multitracer laboratory experiments. Environ Sci Tech 2010;44:688-93. doi: 10.1021/Es9023964.

[51] Chiogna G, Cirpka OA, Grathwohl P, Rolle M. Relevance of local compoundspecific transverse dispersion for conservative and reactive mixing in heterogeneous porous media. Water Resour Res 2011;47:W07540. doi: 10.1029/2010wr010270.

[52] Rasa E, Chapman SW, Bekins BA, Fogg GE, Scow KM, Mackay DM. Role of back diffusion and biodegradation reactions in sustaining an MTBE/TBA plume in alluvial media. J Contam Hydrol 2011;126:235-47. http://dx.doi.org/10.1016/j.jconhyd.2011.08.006. 
882 [53] Rolle M, Chiogna G, Hochstetler DL, Kitanidis PK. On the importance of diffusion 883 and compound-specific mixing for groundwater transport: An investigation from pore to 884 field scale. J J Contam Hydrol 2013;153:51-68. 885 http://dx.doi.org/10.1016/j.jconhyd.2013.07.006.

886 [54] Van Breukelen BM, Rolle M. Transverse hydrodynamic dispersion effects on 887 isotope signals in groundwater chlorinated solvents' plumes. Environ Sci Tech 888 2012;46:7700-8. doi: 10.1021/es301058z.

889 [55] Kitanidis PK. The concept of the Dilution Index. Water Resour Res 1994;30:2011890 26. doi: $10.1029 / 94$ WR00762.

891 [56] Van Cappellen P, J-F Gaillard. Biogeochemical dynamics in aquatic sediments. 892 Reviews in Mineralogy and Geochemistry. 34 (1996) 335-76.

893 [57] Liu CX, Zachara JM, Felmy AR, Gorby Y. An electrodynamics-based model for ion 894 diffusion in microbial polysaccharides. Colloids Surf A and B 2004:38:55-65. doi: 895 10.1016/j.colsurfb.2004.08.003.

896 [58] Alizadeh A, Zhang L, Wang MR. Mixing enhancement of low-Reynolds electro897 osmotic flows in microchannels with temperature-patterned walls. J Colloid Interface Sci 898 2014;431:50-63. doi: 10.1016/j.jcis.2014.05.070.

899 [59] Zhang L, Wang MR. Modeling of electrokinetic reactive transport in micropore 900 using a coupled lattice Boltzmann method. J Geophys Res-Sol Ea 2015;120:2877-90. doi: 901 10.1002/2014JB011812.

902 [60] Bard AJ, Faulkner LR. Electrochemical methods fundamentals and applications. 903 (2nd ed.). John Wiley, New York 2001:718.

904 [61] Cirpka OA, Frind EO, Helmig R. Streamline-oriented grid generation for transport 905 modelling in two-dimensional domains including wells. Adv Water Resour 1999;22:697906 710. doi: 10.1016/s0309-1708(98)00050-5.

907 [62] Guedes de Carvalho JRF, Delgado JMPQ. Overall map and correlation of dispersion 908 data for flow through granular packed beds. Chem Eng Sci 2005;60:365-75. doi: http://dx.doi.org/10.1016/j.ces.2004.07.121.

[63] Rolle M, Hochstetler DL, Chiogna G, Kitanidis PK, Grathwohl P. Experimental investigation and pore-scale modeling interpretation of compound-specific transverse dispersion in porous media. Trans Porous Med 2012;93:347-62. doi: 10.1007/s11242012-9953-8.

[64] Archie GE. The electrical resistivity $\log$ as an aid in determining some reservoir characteristics. Trans AIME; 146.

[65] Boving TB, P Grathwohl. Tracer diffusion coefficients in sedimentary rocks: correlation to porosity and hydraulic conductivity. J Contam Hydrol 2001; 53:85-100. doi: Doi 10.1016/S0169-7722(01)00138-3.

[66] Scheidegger AE. General theory of dispersion in porous media. Journal of Geophys Res 1961;66:3273-8. doi: 10.1029/JZ066i010p03273.

[67] Bijeljic B, Muggeridge AH, Blunt MJ. Pore-scale modeling of longitudinal dispersion. Water Resour Res 2004;40:W11501. doi: 10.1029/2004wr003567.

[68] Hazen A. Some physical properties of sands and gravels: with special reference to their use in filtration. Ann Rep State Board of Health Mass 1892;24:541-556.

[69] Eckert D, Rolle M, Cirpka OA. Numerical simulation of isotope fractionation in steady-state bioreactive transport controlled by transverse mixing. J Contam Hydrol 2012;140-141:95-106. doi: http://dx.doi.org/10.1016/j.jconhyd.2012.08.010. 
928 [70] Cirpka OA, Frind EO, Helmig R. Numerical methods for reactive transport on 929 rectangular and streamline-oriented grids. Adv Water Resour 199;22:711-28. 930 http://dx.doi.org/10.1016/S0309-1708(98)00051-7.

931 [71] Davis T, Duff I. An unsymmetric-pattern multifrontal method for sparse LU 932 factorization. SIAM J Matrix Anal 1997;18:140-58. doi: 10.1137/S0895479894246905.

933 [72] Leij FJ, Skaggs TH, van Genuchten MT. Analytical solutions for solute transport in 934 three-dimensional semi-infinite porous media. Water Resour Res 1991;27:2719-33. doi: 935 10.1029/91WR01912.

936 [73] van Genuchten MT, Leij FJ, Skaggs TH, Toride N, Bradford SA, Pontedeiro EM. 937 Exact analytical solutions for contaminant transport in rivers 1 . The equilibrium 938 advection-dispersion equation. J Hydrol Hydromech 2013;61:146-60. doi: 10.2478/johh939 2013-0020.

940 [74] Lasaga AC. Kinetic theory in the earth sciences. Princeton University Press, 941 Princeton, N.J 1998.

942 [75] Tartakovsky AM, Redden G, Lichtner PC, Scheibe TD, Meakin P. Mixing-induced 943 precipitation: Experimental study and multiscale numerical analysis. Water Resour Res 944 2008;44:W06s04. doi: 10.1029/2006wr005725.

945 [76] Rolle M, Eberhardt C, Chiogna G, Cirpka OA, Grathwohl P. Enhancement of 946 dilution and transverse reactive mixing in porous media: Experiments and model-based interpretation. J Contam Hydrol 2009;110:130-42. doi: 10.1016/j.jconhyd.2009.10.003.

[77] Rolle M, Kitanidis PK. Effects of compound-specific dilution on transient transport and solute breakthrough: A pore-scale analysis. Adv Water Resour 2014;71:186-99. http://dx.doi.org/10.1016/j.advwatres.2014.06.012.

[78] Sudicky EA. A natural gradient experiment on solute transport in a sand aquifer: Spatial variability of hydraulic conductivity and its role in the dispersion process. Water Resour Res 1986;22:2069-82. doi: 10.1029/WR022i013p02069.

[79] Dykaar BB, Kitanidis PK. Determination of the effective hydraulic conductivity for heterogeneous porous media using a numerical spectral approach: 1. Method. Water Resour Res. 1992;28:1155-66. doi: 10.1029/91WR03084.

[80] Yang C, J Samper. Numerical evaluation of multicomponent cation exchange reactive transport in physically and geochemically heterogeneous porous media. Computat Geosci 2009;13:391-404. doi: 10.1007/s10596-009-9127-0.

960 [81] Christiansen JS, Engesgaard PK, Bjerg PL. A physically and chemically 961 heterogeneous aquifer: field study and reactive transport modelling. In: Groundwater 962 Quality: Remediation and Protection, Proceedings of the GQ'98 Conference, IAHS Press, 963 Wallingford 1998:329-36.

964 [82] Jacques D, Mouvet C, Mohanty B, Vereecken H, Feyen J. Spatial variability of 965 atrazine sorption parameters and other soil properties in a podzoluvisol. J Contam Hydrol 1999;36:31-52. http://dx.doi.org/10.1016/S0169-7722(98)00141-7.

[83] Samper J, Yang C. Stochastic analysis of transport and multicomponent competitive monovalent cation exchange in aquifers. Geosphere 2006;2:102-12. doi: $10.1130 /$ ges00030.1.

[84] Kjøller C, Postma D, Larsen F. Groundwater acidification and the mobilization of trace metals in a sandy aquifer. Environ Sci Tech 2004;38:2829-35. doi: $10.1021 / \mathrm{es} 030133 \mathrm{v}$. 
973 [85] Prigiobbe V, Bryant SL. pH-dependent transport of metal cations in porous media. 974 Environ Sci Tech 2014;48:3752-9. doi: 10.1021/es403695r.

975 [86] Li L, Salehikhoo F, Brantley SL, Heidari P. Spatial zonation limits magnesite 976 dissolution in porous media. Geochim Cosmochim Acta 2014;126:555-73. 977 http://dx.doi.org/10.1016/j.gca.2013.10.051.

978 [87] Molins S, Trebotich D, Steefel CI, Shen CP. An investigation of the effect of pore 979 scale flow on average geochemical reaction rates using direct numerical simulation. 980 Water Resour Res 2012;48:W03527. doi: 10.1029/2011wr011404.

981 [88] Haberer CM, Muniruzzaman M, Grathwohl P, Rolle M. Diffusive/Dispersive and 982 reactive fronts in porous media: Fe (II)-Oxidation at the unsaturated/saturated interface. 983 Vadose Zone J 2015;14(5). doi: http://dx.doi.org/10.2136/vzj2014.07.0091.

984 [89] Fakhreddine S, Lee J, Kitanidis PK, Fendorf S, Rolle M. Imaging geochemical 985 heterogeneities using inverse reactive transport modeling: An example relevant for 986 characterizing arsenic mobilization and distribution. Adv Water Resour 2016;88: 186-97. 987 http://dx.doi.org/10.1016/j.advwatres.2015.12.005.

988 [90] Redden G, Fox D, Zhang C, Fujita Y, Guo L, Huang $\mathrm{H} . \mathrm{CaCO}_{3}$ precipitation, 989 transport and sensing in porous media with in situ generation of reactants. Environ Sci 990 Tech 2014;48:542-9. doi: 10.1021/es4029777.

991 [91] Chiogna G, Rolle M, Bellin A, Cirpka OA. Helicity and flow topology in three992 dimensional anisotropic porous media. Adv Water Resour 2014;73:134-43. 993 http://dx.doi.org/10.1016/j.advwatres.2014.06.017.

994 [92] Ye Y, G Chiogna, OA Cirpka, P Grathwohl, M Rolle. experimental evidence of 995 helical flow in porous media. Phys Rev Lett 2015;115:194502. doi: 996 10.1103/Physrevlett.115.194502.

997 [93] Cirpka OA, Chiogna G, Rolle M, Bellin A. Transverse mixing in three-dimensional 998 nonstationary anisotropic heterogeneous porous media. Water Resour Res 2015;51:241999 60. doi: 10.1002/2014WR015331. 